\title{
Interlink Converter with Linear Quadratic Regulator Based Current Control for Hybrid AC/DC Microgrid
}

\author{
Dwi Riana Aryani, Jung-Su Kim (D) and Hwachang Song * \\ Department of Electrical and Information Engineering, Seoul National University of Science and Technology, \\ Seoul 01811, Korea; dwiriana@seoultech.ac.kr (D.R.A.); jungsu@seoultech.ac.kr (J.-S.K.) \\ * Correspondence: hcsong@seoultech.ac.kr; Tel.: +82-2-970-6403
}

Received: 26 September 2017; Accepted: 1 November 2017; Published: 8 November 2017

\begin{abstract}
A hybrid alternate current/direct current (AC/DC) microgrid consists of an AC subgrid and a DC subgrid, and the subgrids are connected through the interlink bidirectional AC/DC converter. In the stand-alone operation mode, it is desirable that the interlink bidirectional AC/DC converter manages proportional power sharing between the subgrids by transferring power from the under-loaded subgrid to the over-loaded one. In terms of system security, the interlink bidirectional AC/DC converter takes an important role, so proper control strategies need to be established. In addition, it is assumed that a battery energy storage system is installed in one subgrid, and the coordinated control of interlink bidirectional AC/DC converter and battery energy storage system converter is required so that the power sharing scheme between subgrids becomes more efficient. For the purpose of designing a tracking controller for the power sharing by interlink bidirectional $\mathrm{AC} / \mathrm{DC}$ converter in a hybrid AC/DC microgrid, a droop control method generates a power reference for interlink bidirectional AC/DC converter based on the deviation of the system frequency and voltages first and then interlink bidirectional AC/DC converter needs to transfer the power reference to the over-loaded subgrid. For efficiency of this power transferring, a linear quadratic regulator with exponential weighting for the current regulation of interlink bidirectional AC/DC converter is designed in such a way that the resulting microgrid can operate robustly against various uncertainties and the power sharing is carried out quickly. Simulation results show that the proposed interlink bidirectional AC/DC converter control strategy provides robust and efficient power sharing scheme between the subgrids without deteriorating the secure system operation.
\end{abstract}

Keywords: battery energy storage system; hybrid AC/DC microgrid; interlink bidirectional AC/DC converter; linear quadratic regulator; power sharing

\section{Introduction}

Microgrids comprise low voltage distribution systems with distributed energy resources (microturbines, fuel cells, photovoltaic system, etc.) together with storage devices (flywheels, energy capacitors and batteries) and flexible loads [1]. Microgrids can be operated in grid-connected mode and stand-alone mode, and depending on the mode, the target of control and operation will change. Efficient managing and coordinating the operation of the available resources in microgrids can provide several benefits from the viewpoint of economy and system performance. For instance, in [2] a decentralized energy management system is designed for autonomous polygeneration microgrids using the intelligent multi-agent systems, and in [3] an integrated framework of agent-based modelling and robust optimization is proposed, where both energy management systems show improvements in financial and operational terms.

A new form of microgrid was proposed which is known as hybrid AC/DC microgrids integrating various AC/DC loads, distributed energy resources (DERs), and energy storages in one system [4]. 
In the system, the AC generators, loads, and storage systems are connected to AC subgrids, while the DC assets are installed in DC subgrids. For those microgrids, interlink converters (ICs) are used to interconnect $\mathrm{AC}$ and $\mathrm{DC}$ subgrids, and their main function is to exchange the power between AC and DC subgrids. In [5], an overview of power management strategies was given for a hybrid AC/DC microgrid system, which includes different system structures (AC-coupled, DC-coupled, and AC/DC-coupled hybrid microgrids), different operation modes, a thorough study of various power management and control schemes in both steady state and transient conditions, and examples of power management and control strategies.

For hybrid AC/DC microgrids in islanded mode, it is important to determine the settings for maximization of steady-state stability margin. In [6], an optimal power flow (OPF) formulation for loadability maximization of stand-alone converter-dominated hybrid AC/DC microgrids is presented. In addition, cost-effective control strategies are desirable in the normal operation of hybrid microgrids. In [7], an economic model predictive control (EMPC) approach is employed for cost-effective supervision of microgrid systems by taking the battery lifetime as the constraint.

All the converters in a hybrid microgrid need to have their own control objectives and their output need to be managed in coordinated control with the power support from the external grid when the imbalance of the DERs and loads happens in the grid. The microgrid also can support the grid by controlling active and reactive powers transferred to the grid. When the system gets into stand-alone mode, coordinating converter controls of sources and energy storages would be more challenging to maintain system security. The coordinated control is required not only to share power proportionally among sources within each subgrid, but also to support power between the subgrids, and this in turn makes the control strategy of IC very important. In [8], hierarchical control system for parallel ICs is divided into three levels; the primary control level presents the droop control as the local control, the secondary control level is designed to eliminate the deviation produced by the primary control, and the tertiary control level is employed to perform the connection to an external system.

In the literature, various droop control methods have been proposed for energy resources for individual AC and DC microgrids to share the load demand in proportion to the power rating of each DER [9]. Besides, by applying droop control, the system does not require any communication among the sources since any action of each source is decided based on local measurements. Thus, droop control methods are suitable for microgrid systems with distributed generation assets.

In hybrid AC/DC microgrid system, IC control can be applied using the droop control scheme for power sharing between AC and DC subgrids [10]. In [11], droop control with frequency and voltage deviation based balancing inputs have been performed, indeed merging them into one droop characteristic for the IC active power reference. While in [12] the droop control of IC considers the state of charge constraints of the battery which is installed in DC subgrid. In order to improve the droop control strategy of the IC, a sliding mode control-based current control is presented in [13]. The objective of the droop control strategy of the IC can be designed differently according to the operation mode [14].

Other control strategies have been proposed to manage IC such as seamless switch control method [15], H-infinity control [16], and adaptive neural network-based control [17]. Control of multiple ICs was also proposed, as in [18] by using distributed coordination control, as well as in [19] which presents an improved control method with circulating current reduction and accurate power sharing. While adjustable reference current coefficients to enable the flexible current sharing among parallel ICs is proposed in [20].

From the viewpoint of control design, IC is a multi-input multi-output (MIMO) system for which it is not easy to tune PI control parameters. Besides, since AC/DC hybrid microgrid operates with various different modes, IC has to work robustly for various different operating conditions. Moreover, in order for secure operation it is quite essential to transfer power from the under-loaded subgrid to over-loaded subgrid rapidly if necessary. 
In order to take these situations into account in a controller design for IC, a linear quadratic regulator (LQR) with exponential weighting is employed. Based on the deviation of frequency in AC subgrid and that of voltage in DC subgrid, a droop control method produces a power reference which has to be transferred by IC. Then, using the power reference, a LQR is designed for offset-free tracking of IC. In the middle of designing the LQR, exponential weighting is used for the sake of robust performance and fast response of IC. In [21], LQR technique is proposed for the current control of grid-connected inverter by considering its advantages, such as good transient response and excellent stability margins. Other applications of LQR for converter control are on three-phase power converters Space Vector Pulse Width Modulation (SVPWM) [22], multi-loop linear control strategy for UPS inverter [23], and a three-phase three-switch three-level AC/DC converter [24].

For demonstrating the performance of the proposed control, simulation study is done for several typical operating conditions. The simulation results show that: (1) power is transferred between subgrids rapidly thanks to the fast response of IC; (2) the hybrid microgrid operates robustly against various operation conditions due to robust tracking performance of IC; and (3) it is easy to adjust LQR parameters to enhance performance of IC. Note that the fair comparison, the proposed scheme is compared with well-tuned conventional PI controller.

\section{Hybrid AC/DC Microgrid Operation}

A simple model of a hybrid AC/DC microgrid is illustrated as in Figure 1. Power sources in the AC subgrid are from a 100-kVA diesel generator set and a 20-kW wind turbine. Meanwhile, in the DC subgrid a $25-\mathrm{kW}$ photovoltaic (PV) array is connected through a DC/DC boost converter. A Battery Energy Storage Systems (BESS) with rating $30 \mathrm{~kW}$ is connected to the DC bus through a bidirectional DC/DC buck-boost converter. The rated voltages for AC and DC buses are $220 \mathrm{~V}$ (line to neutral) and $600 \mathrm{~V}$, respectively. A $10 \mathrm{kVAR}$ capacitor bank is installed in the AC subgrid to support reactive power regulation. The AC and DC microgrid are connected through an interlink bidirectional AC/DC converter (IC) with a R-L filter.

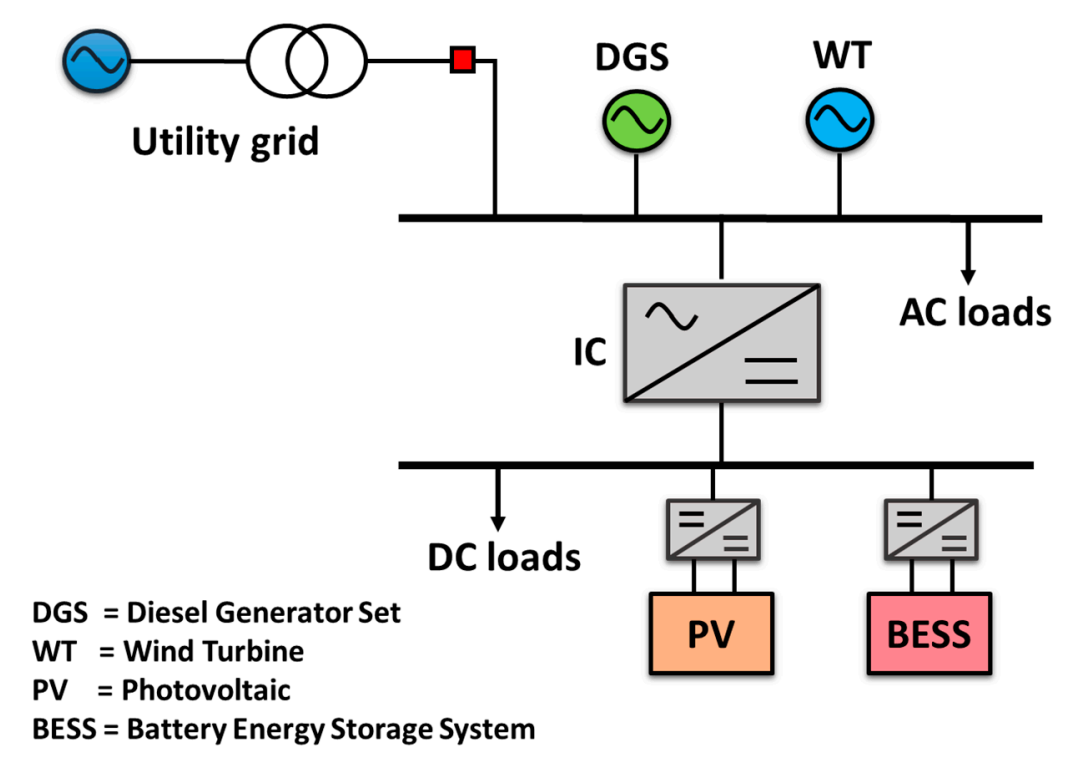

Figure 1. Proposed hybrid AC/DC microgrid system.

A utility grid with rated voltage $22.9 \mathrm{kV}$ is connected to the AC bus. In grid-connected mode, the system stability is maintained well as the utility grid could satisfy the demand of the entire system. When the system changes to stand-alone mode, each DERs coordinating with BESS will supply all the load demand. The security of the over-loaded subgrid might be deteriorated, thus the source and 
BESS converters are expected to manage power sharing within each subgrid in a coordinated control with IC who will manage the power sharing between both subgrids.

\section{Droop Control Strategy for Individual Subgrids}

\subsection{Droop Control of AC Microgrid}

In an AC system, power variations affect the changes in frequency and voltage. When frequency deviations occur in the system because of the imbalance of active power, the droop control will restore the system by changing the active power output of the controlled sources, defined by (1). $P_{a c}$ is the active power generated by the droop control of the corresponding source with droop characteristic $R_{p, a c}$ due to the frequency change, with the measured frequency $f_{a c}$. Meanwhile, $f_{\min , a c}$ is the minimum allowable frequency and $P_{\max , a c}$ is the maximum active power of the AC droop control scheme.

Droop control also could be applied to regulate AC system voltage by changing the reactive power output as given in Equation (2), where $Q_{a c}$ is the reactive power produced by the droop control with droop characteristic $R_{q, a c}$, while $V_{a c}$ is the measured AC voltage. $V_{m i n, a c}$ is the minimum allowable voltage and $Q_{\max , a c}$ is the maximum reactive power of the AC droop control scheme. In AC subgrid with multiple sources, the droop control will share the total load demand in proportion to each source ratings. Figures 2 and 3 show the frequency-active power $(f-P)$ and voltage-reactive power $\left(V_{a c}-Q\right)$ droop characteristic curves.

$$
\begin{aligned}
P_{a c} & =\frac{1}{R_{p, a c}}\left(f_{a c}-f_{\min , a c}\right)+P_{\max , a c} \\
Q_{a c} & =\frac{1}{R_{q, a c}}\left(V_{a c}-V_{\min , a c}\right)+Q_{\max , a c} .
\end{aligned}
$$

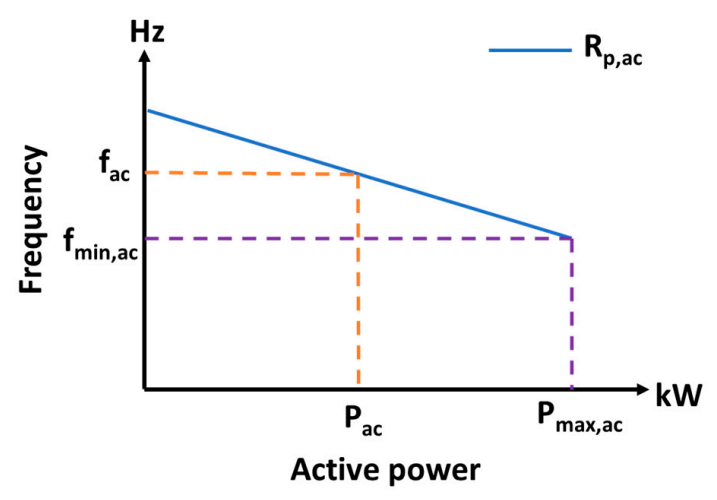

Figure 2. $f$ - $P$ droop characteristic in the AC microgrid.

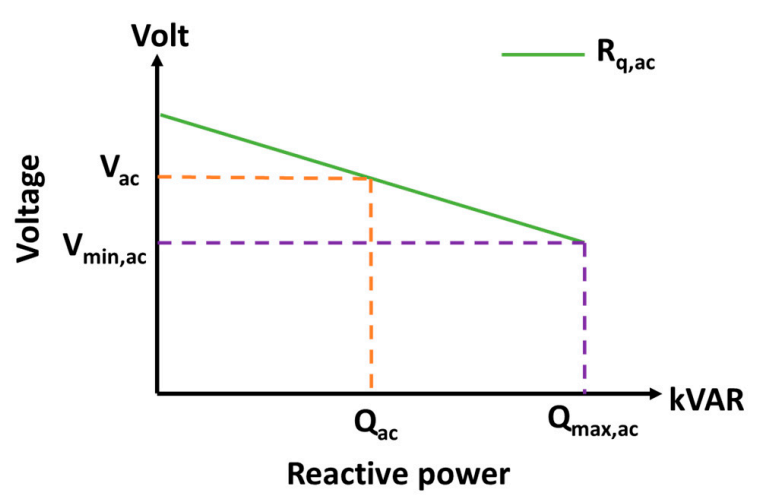

Figure 3. $V_{a c}-Q$ droop characteristic in the AC microgrid. 


\subsection{Droop Control of the DC Microgrid}

In the DC microgrid, variations in active power are related to the change in the voltage. There is no control scheme for reactive power sharing and frequency. The droop control scheme for voltage regulation is defined by Equation (3) with Figure 4, where $P_{d c}$ is the active power generated by the droop control with droop characteristic $R_{d c}, V_{d c}$ is the measured DC voltage, $V_{\min , d c}$ is the minimum allowable DC voltage and $P_{\max , d c}$ is the maximum active power of the DC droop control scheme:

$$
P_{d c}=\frac{1}{R_{d c}}\left(V_{d c}-V_{\min , d c}\right)+P_{\max , d c} .
$$

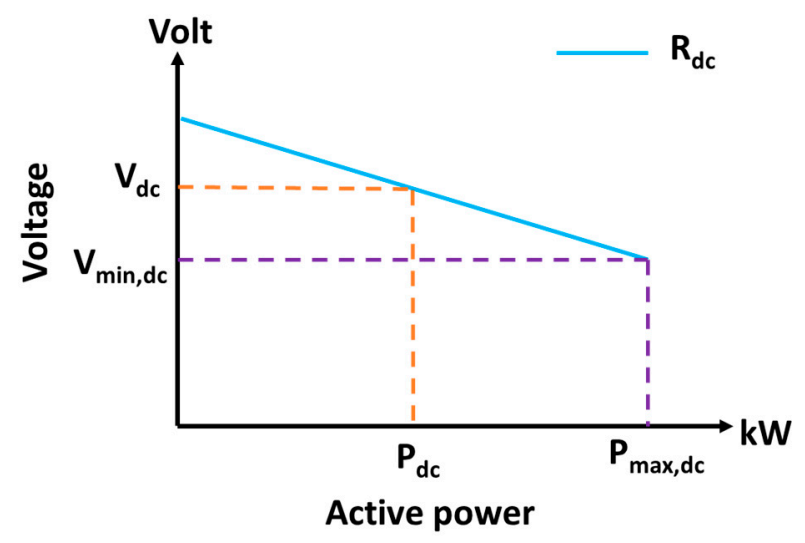

Figure 4. Voltage-active power $\left(V_{d c}-P\right)$ droop characteristic in the DC microgrid.

\section{IC Control Strategy}

\subsection{Droop Control Strategy in Hybrid AC/DC Microgrid}

The IC configuration in this paper is assembled by a standard bidirectional AC-DC converter. A capacitor is employed at the common dc link as well as RL filters at the point of common coupling (PCC) to the AC subgrid for filtering purpose. Figure 5 displays the proposed IC configuration.

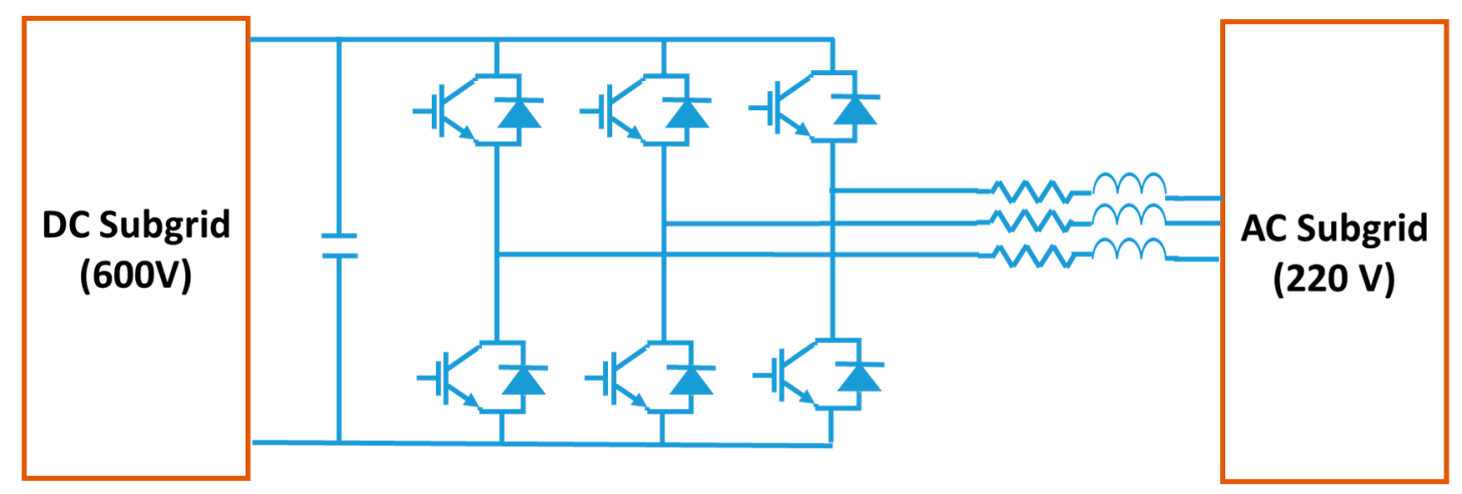

Figure 5. IC configuration.

During the stand-alone operation, the hybrid AC/DC microgrid might experience power imbalance in one or both subgrids. As the primary control, the droop control of the sources would share the power in proportion to each rating. If the power imbalance in the corresponding subgrid still happens even though the sources already increase their output power, power sharing between the subgrids needs to be done in order to secure the system operation. Thus, the droop control could be 
applied to IC in order to manage the power transfer from subgrid with excessive power to the one with deficit power. In other word, the IC acts as a supplier for one subgrid and as a load for the other.

As mentioned previously, active power sharing associates to the frequency change in AC subgrid, while in DC subgrid it is related to the voltage change. Thus, active power sharing is performed by enforcing the frequency deviation on the AC subgrid $\Delta f$ to be equal to the bus voltage deviation on the DC microgrid $\Delta V_{d c}$ [25]. Since both parameters have different units, the measurements need to be normalized in per unit (p.u.) as given in Equations (4) and (5):

$$
\begin{gathered}
\Delta f=\frac{f_{r e f}-f_{m}}{0.5\left(f_{\max }-f_{\text {min }}\right)}, \\
\Delta V_{d c}=\frac{V_{d c, \text { ref }}-V_{d c, m}}{0.5\left(V_{d c, \text { max }}-V_{d c, \text { min }}\right)},
\end{gathered}
$$

where $f_{m}, f_{r e f}, V_{d c, m}$, and $V_{d c, r e f}$ are the measured frequency, the reference of frequency, the measured DC voltage, and the reference of DC voltage, respectively, while $f_{\max }, f_{\min }, V_{d c, \max }$, and $V_{d c, \min }$ are the maximum frequency, the minimum frequency, the maximum DC voltage, and the minimum DC voltage for the droop control of IC.

The difference of both values in Equations (4) and (5) will be the input of the proportional controller, where the gain parameters are $1 / R_{p 1}$ for the frequency deviation input and $1 / R_{p 2}$ for the DC voltage deviation input. The difference of both control outputs generates the active power reference of IC $P_{I C}$ as described in Equation (6). For the generated $P_{I C}$ sign, power flow from DC to AC subgrids is assumed as the positive power injection, and the opposite way is the negative power injection, as shown in Figure 6:

$$
P_{I C}=\left(\Delta f \times \frac{1}{R_{p 1}}\right)-\left(\Delta V_{d c} \times \frac{1}{R_{p 2}}\right)
$$

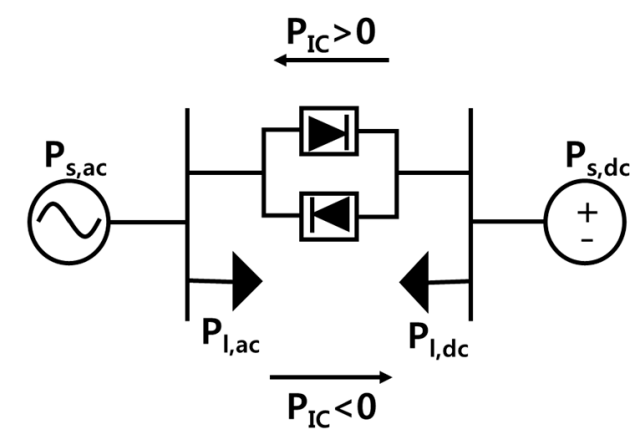

Figure 6. IC power injection.

The droop characteristics of IC droop control in this paper are designed as in Figure 7. Those values are determined based on the ratings and allowable deviations in each subgrid. Normal operation of system frequency is $58 \mathrm{~Hz}<f<62 \mathrm{~Hz}$, meanwhile for DC voltage is $550 \mathrm{~V}<V_{d c}<650 \mathrm{~V}$. Power injection through IC is limited to $20 \mathrm{~kW}$ considering the DC subgrid rating as the lowest rated subgrid, so the transfer power would not overstress the DC subgrid. Another issue needs to be considered is if the transferred power to the AC subgrid as the higher rated subgrid is not sufficient due to the limited power provided by DC subgrid. In such condition, load shedding in AC subgrid needs to be taken in order to maintain the system security. 


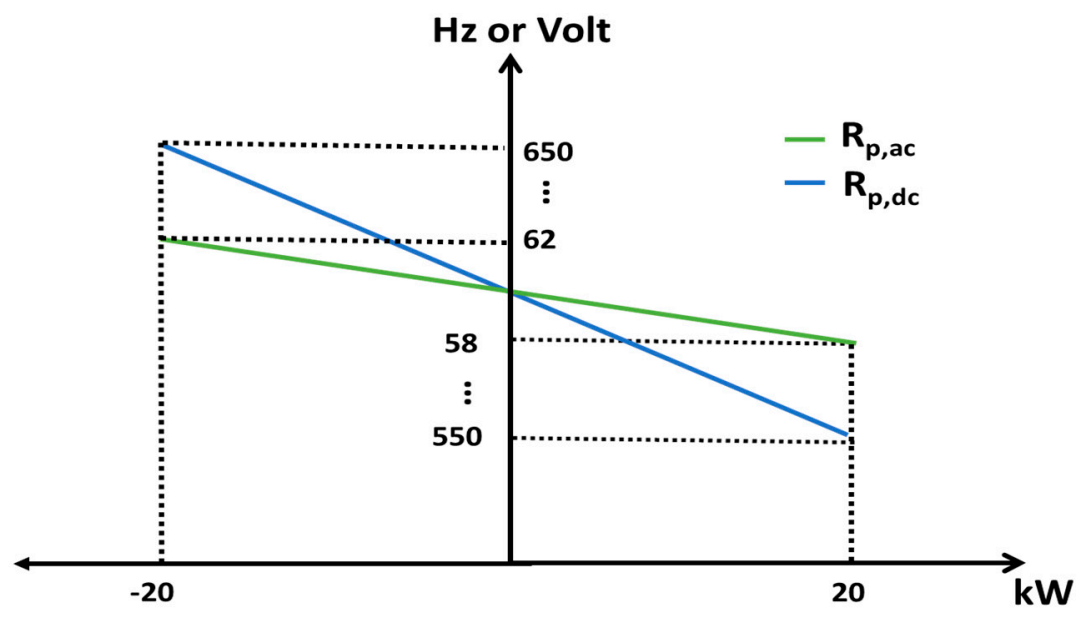

Figure 7. Designed frequency-DC voltage-active power droop characteristics for IC droop control.

The control strategy to generate reactive power reference $Q_{I C}$ is similar to the one in AC microgrid. The reactive power variations affect the change in $\mathrm{AC}$ voltage deviation as in equation below:

$$
Q_{I C}=\left(V_{a c, r e f}-V_{a c, m}\right) \times \frac{1}{R_{q}},
$$

where $V_{a c, r e f}, V_{a c, m}$, and $R_{q}$ are reference AC voltage, measured AC voltage, and $V_{a c}-Q$ droop characteristic. $Q_{I C}$ will become zero if power flows from the AC to the DC subgrid as the DC subgrid does not require reactive power.

During stand-alone mode, the IC control objective depends on the battery operation mode in order to maintain power sharing between the subgrids more efficiently. In this paper, battery is installed in DC subgrid and the battery converter operates based on the voltage of the DC link capacitor. It turns out that DC subgrid is always maintained by the battery as long as the battery state of charge (SOC) meets the required level of the operation mode [26]. In other words, when power imbalance happens in the system, and the battery is able to charge or discharge the power based to the voltage deviation in DC subgrid, the reference of IC power injection is only determined by the deviation in AC subgrid frequency. Meanwhile, if battery is not able to operate because of its SOC level, IC is managed to share the power proportionally between both subgrids by balancing the frequency and DC voltage deviations as described in (6). Such scheme can be applied by varying the gain parameters of the IC droop control in accordance to the battery operation mode, as described in Equation (8):

$$
\frac{1}{R_{p 2}}=\left\{\begin{array}{c}
\frac{\Delta P_{d c}}{\Delta V_{d c}}, \text { when } P_{b a t}=0 \\
0, \text { when } P_{b a t} \neq 0
\end{array}\right.
$$

Figure 8 shows the selection of the gain parameter $\frac{1}{R_{p 2}}$ of the IC droop controller based on the battery operation. When power imbalance between total sources $\sum P_{s, d c}$ and total loads $\sum P_{l, d c}$ in DC subgrid happened, battery would operate to charge or discharge power depending on the load demand in that subgrid. If net power $P_{n e t}$ is more than zero, or there is excessive power in DC subgrid, battery needs to charge the surplus power so the voltage in DC subgrid could be maintained in its allowable operation range. Meanwhile, when $P_{n e t}$ is less than zero, or there is deficient power in DC subgrid, battery is required to discharge some amount of power to restore the voltage to its normal operating point. In both conditions, since DC subgrid voltage is maintained by the battery, IC generates the reference of power injection only based on the power imbalance in AC subgrid in order for the efficient control of the hybrid microgrid. Such strategy is performed by setting the gain parameter $\frac{1}{R_{p 2}}$ of the droop control in Equation (6) to zero. Besides, if battery is not able to charge the excessive 
power in DC subgrid or it could not discharge power when power deficient happened, $\frac{1}{R_{p 2}}$ is set to be $\frac{\Delta P_{d c}}{\Delta V_{d c}}$ so that the generated reference of IC power injection is based on the power imbalance in both subgrids. It turns out that IC manages the proportional power sharing between both subgrids while battery is not operating due to the limitation of the SOC. Some counter measures need to be done if the power sharing scheme could not restore the frequency and voltage deviation so the system stability and security would not be deteriorated, such as performing the load shedding when the frequency or voltages drop beyond the allowable limits, or turning on the dump load when frequency or voltages are higher than its maximum limit.

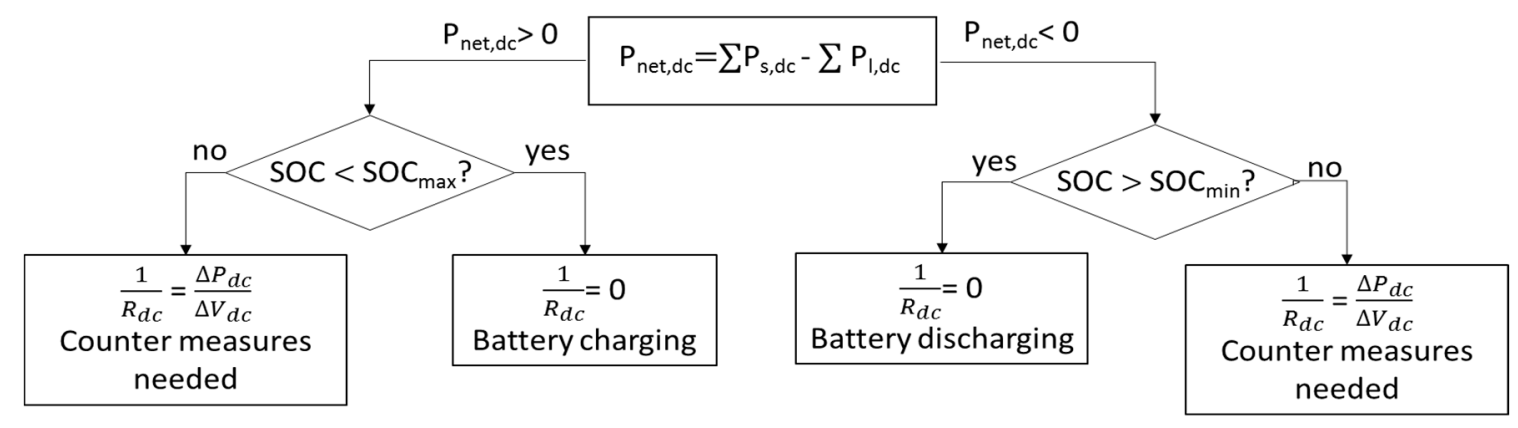

Figure 8. Gain parameter $\frac{1}{R_{p, d c}}$ selection for IC droop control.

In case of the hybrid microgrid is connected to the utility grid, the BESS is only allowed to charge the excessive power as long as the SOC is below its maximum level. BESS is prevented to discharge the power as the utility grid is assumed to be able to support the power deficient in the microgrid in order to operate the system efficiently. In this case, the gain parameter $\frac{1}{R_{p 1}}$ of the IC droop control in (6) is set to be zero, so the IC droop control is performed based on the power imbalance in DC subgrid.

\subsection{Optimized IC Current Control Using LQR}

In this paper, the generated active and reactive powers are passed to the proportional controllers to obtain the reference tracking of current $I_{d, r e f}$ and $I_{q, r e f}$ respectively. The measured three phase voltage and current at the PCC of IC to the AC subgrid are transformed into $d-q$ axis by using PLL control. After transforming the voltage and current to $d-q$ form, the error signal of $I_{d, r e f}-I_{d}$ and $I_{q, \text { ref }}-I_{q}$ are passed to the respective controllers for the current tracking scheme. The converter input voltages $V_{d}$ and $V_{q}$ are transformed back to $a$ - $b$-c form and compared with the switching frequency as the input signal for pulse width modulator. The IC droop control scheme is shown in Figure 9, while Figure 10 presents the IC current control with PI and LQR controller.

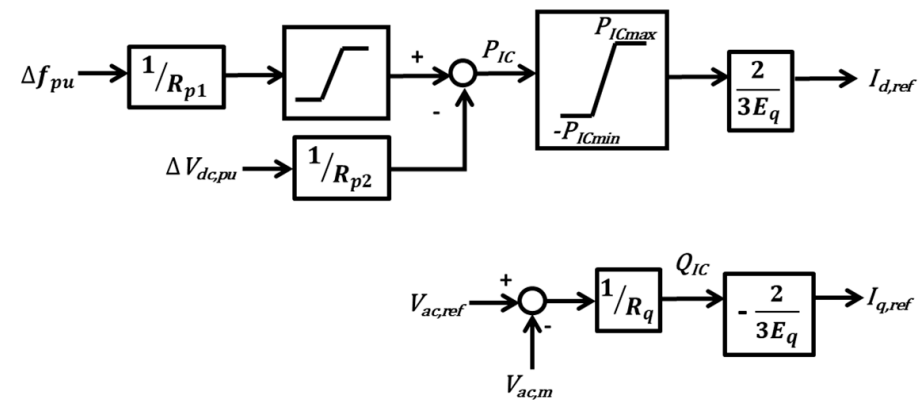

Figure 9. Proposed droop control for IC control scheme in stand-alone hybrid microgrid. 

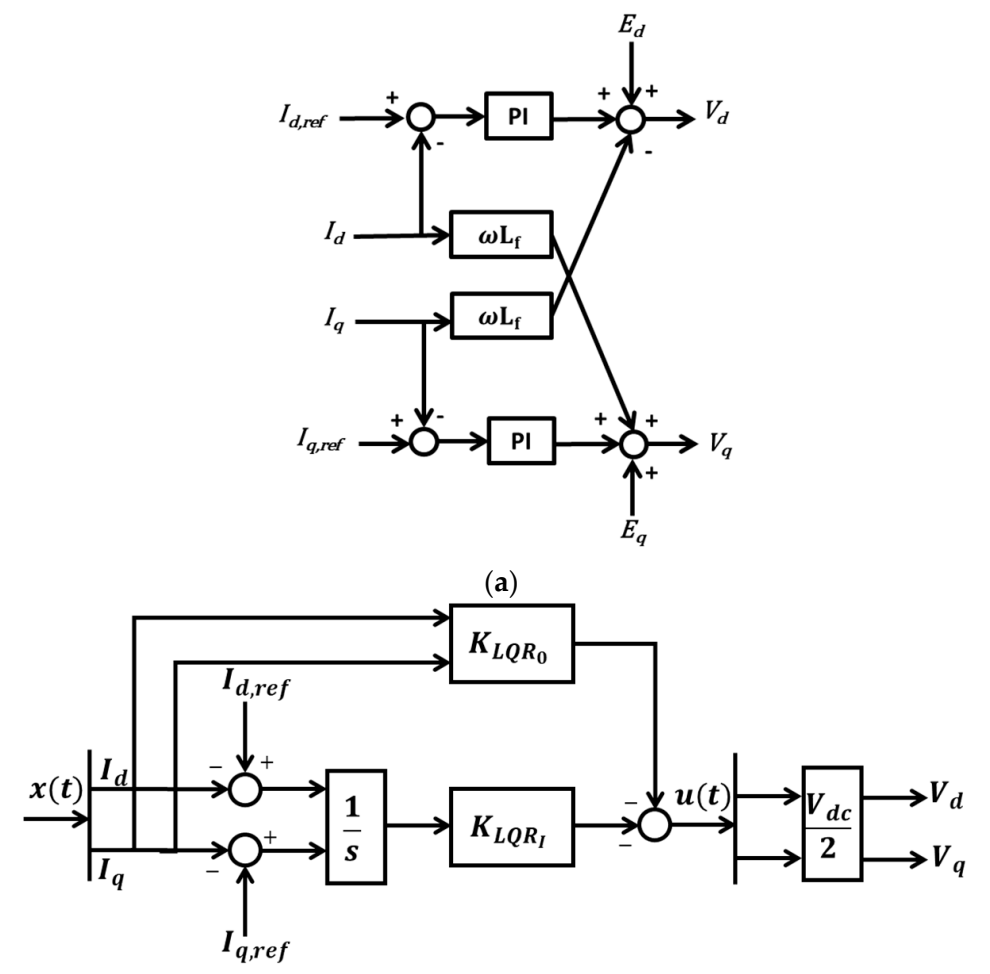

(b)

Figure 10. IC current control scheme with (a) PI controller (b) the proposed LQR.

LQR is designed for the current tracking controller as shown in Figure 10b. In order to design the LQR, a state space model of the voltage source converter (VSC) is considered as given in Figure 11.

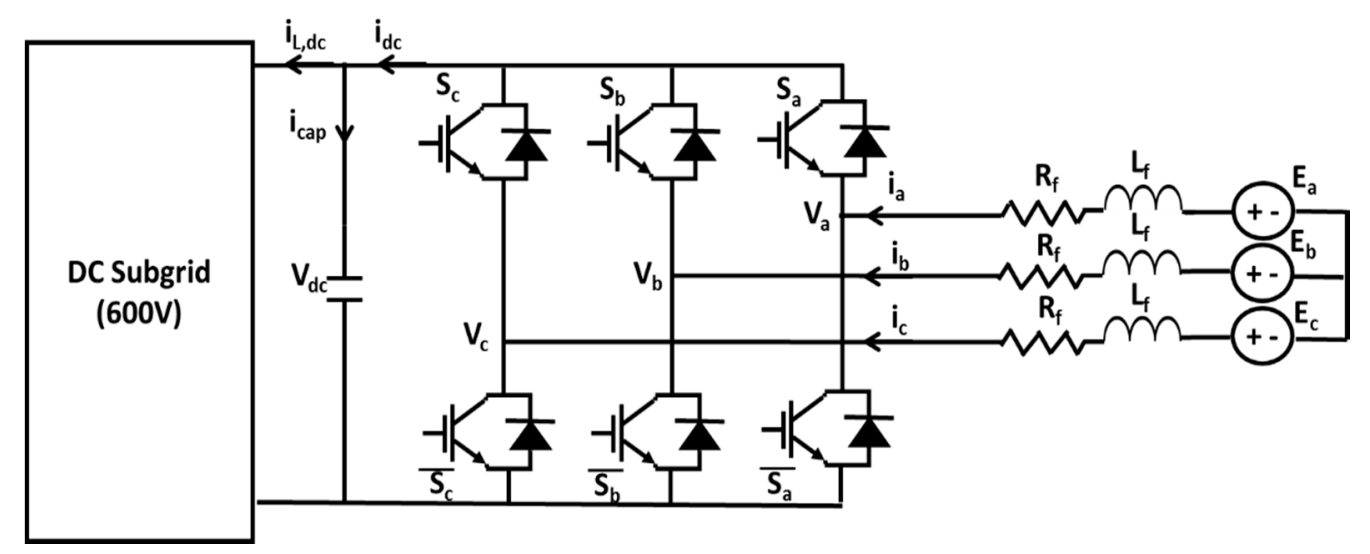

Figure 11. VSC type IC model.

According to the Kirchoff Voltage law, the three-phase voltage at the AC side is as follows:

$$
V_{a b c}(t)=-R_{f} i_{a b c}(t)-L_{f} \frac{d i_{a b c}(t)}{d t}+E_{a b c}(t),
$$

where $R_{f}$ and $L_{f}$ are filter resistance and inductance, respectively:

$$
i_{a b c}(t)=\left[\begin{array}{c}
i_{a}(t) \\
i_{b}(t) \\
i_{c}(t)
\end{array}\right], V_{a b c}(t)=\left[\begin{array}{c}
V_{a(t)} \\
V_{b(t)} \\
V_{c}(t)
\end{array}\right], E_{a b c}(t)=\left[\begin{array}{c}
E_{a}(t) \\
E_{b}(t) \\
E_{c}(t)
\end{array}\right] .
$$


The current equation becomes:

$$
\frac{d i_{a b c}(t)}{d t}=-\frac{R_{f}}{L_{f}} i_{a b c}(t)-\frac{V_{a b c}(t)}{L_{f}}+\frac{E_{a b c}(t)}{L_{f}} .
$$

The voltages at the input of the converter are:

$$
V_{a}(t)=\frac{1}{2}\left(1+p_{a}(t)\right) V_{d c}(t) V_{b}(t)=\frac{1}{2}\left(1+p_{b}(t)\right) V_{d c}(t) V_{c}(t)=\frac{1}{2}\left(1+p_{c}(t)\right) V_{d c}(t) .
$$

The switches operate in continuous conduction mode, where two switches in each leg of the bidirectional AC-DC converter should be operated in a complementary mode to avoid short circuit. The switching states of the bidirectional AC-DC converter is determined by the gating signal $p_{a}, p_{b}$, or $p_{c}$ as:

$$
\begin{aligned}
& p_{a}=\left\{\begin{array}{l}
1, \text { when } s_{a} \text { is on and } \overline{s_{a}} \text { is off } \\
-1, \text { when } s_{a} \text { is off } \text { and } \overline{s_{a}} \text { is on }
\end{array}\right. \\
& p_{b}=\left\{\begin{array}{l}
1, \text { when } s_{b} \text { is on and } \overline{s_{b}} \text { is off } \\
-1, \text { when } s_{b} \text { is off } \text { and } \overline{s_{b}} \text { is on }
\end{array}\right. \\
& p_{c}=\left\{\begin{array}{l}
1, \text { when } s_{c} \text { is on and } \overline{s_{c}} \text { is off } \\
-1, \text { when } s_{\mathcal{c}} \text { is off and } \overline{s_{c}} \text { is on. }
\end{array}\right.
\end{aligned}
$$

$V_{a b c}$ depends on $V_{d c}$ and switch states as follows [27]:

$$
V_{a b c}(t)=\frac{1}{6} V_{d c}(t) M\left[\begin{array}{l}
p_{a}(t) \\
p_{b}(t) \\
p_{c}(t)
\end{array}\right]
$$

where:

$$
M=\left[\begin{array}{ccc}
2 & -1 & -1 \\
-1 & 2 & -1 \\
-1 & -1 & 2
\end{array}\right]
$$

The three phase variables are transformed into $d-q$ frame for control design:

$$
\begin{aligned}
& {\left[\begin{array}{l}
E_{d}(t) \\
E_{q}(t)
\end{array}\right]=\frac{2}{3} W(t)\left[\begin{array}{l}
E_{a}(t) \\
E_{b}(t) \\
E_{c}(t)
\end{array}\right],} \\
& {\left[\begin{array}{l}
i_{d}(t) \\
i_{q}(t)
\end{array}\right]=\frac{2}{3} W(t)\left[\begin{array}{l}
i_{a}(t) \\
i_{b}(t) \\
i_{c}(t)
\end{array}\right],} \\
& {\left[\begin{array}{l}
p_{d}(t) \\
p_{q}(t)
\end{array}\right]=\frac{2}{3} W(t)\left[\begin{array}{l}
p_{a}(t) \\
p_{b}(t) \\
p_{c}(t)
\end{array}\right],}
\end{aligned}
$$

where:

$$
W(t)=\left[\begin{array}{ccc}
\cos \theta & \cos \left(\theta-\frac{2 \pi}{3}\right) & \cos \left(\theta-\frac{4 \pi}{3}\right) \\
-\sin \theta & -\sin \left(\theta-\frac{2 \pi}{3}\right) & -\sin \left(\theta-\frac{4 \pi}{3}\right)
\end{array}\right] .
$$

Equation (13) is multiplied by $W$ on both sides and the relation $W(t) M=3 W(t)$ is used:

$$
W(t) V_{a b c}(t)=\frac{1}{2} V_{d c}(t) W(t)\left[\begin{array}{c}
p_{a}(t) \\
p_{b}(t) \\
p_{c}(t)
\end{array}\right]
$$


By substituting Equation (16) into Equation (17):

$$
\frac{2}{3} W(t) V_{a b c}(t)=\frac{1}{2} V_{d c}(t)\left[\begin{array}{l}
p_{d}(t) \\
p_{q}(t)
\end{array}\right] .
$$

From Equations (14)-(17), the three-phase current in Equation (10) is represented in $d-q$ frame:

$$
\begin{aligned}
& \frac{d i_{d}(t)}{d t}=-\frac{R_{f}}{L_{f}} i_{d}(t)+\omega i_{q}(t)-\frac{V_{d c}(t)}{2 L_{f}} p_{d}(t)+\frac{E_{d}(t)}{L_{f}}, \\
& \frac{d i_{q}(t)}{d t}=-\frac{R_{f}}{L_{f}} i_{q}(t)-\omega i_{d}(t)-\frac{V_{d c}(t)}{2 L_{f}} p_{q}(t)+\frac{E_{q}(t)}{L_{f}},
\end{aligned}
$$

where $i_{d}$ is the $d$-axis inverter current, $i_{q}$ is the $q$-axis inverter current, $V_{d}$ is the $d$-axis inverter output voltage, $V_{q}$ is the $q$-axis inverter output voltage, $E_{d}$ is the $d$-axis AC subgrid voltage, $E_{q}$ is the $q$-axis AC subgrid voltage, and $\omega$ is the grid angular frequency.

From the Equations (18) and (19), the system can be designed in a state-space model:

$$
\begin{gathered}
{\left[\begin{array}{c}
\dot{x_{1}}(t) \\
\dot{x_{2}}(t)
\end{array}\right]=\left[\begin{array}{cc}
-\frac{R_{f}}{L_{f}} & \omega \\
-\omega & -\frac{R_{f}}{L_{f}}
\end{array}\right]\left[\begin{array}{c}
x_{1}(t) \\
x_{2}(t)
\end{array}\right]+\left[\begin{array}{cc}
\frac{1}{L_{f}} & 0 \\
0 & \frac{1}{L_{f}}
\end{array}\right]\left(-\frac{V_{d c}}{2}(t)\right)\left[\begin{array}{c}
u_{1}(t) \\
u_{2}(t)
\end{array}\right]+\left[\begin{array}{cc}
\frac{1}{L_{f}} & 0 \\
0 & \frac{1}{L_{f}}
\end{array}\right]\left[\begin{array}{c}
E_{d}(t) \\
E_{q}(t)
\end{array}\right]} \\
{[y(t)]=\left[\begin{array}{cc}
1 & 0 \\
0 & 1
\end{array}\right]\left[\begin{array}{l}
x_{1}(t) \\
x_{2}(t)
\end{array}\right]}
\end{gathered}
$$

where:

$$
\left[\begin{array}{l}
x_{1}(t) \\
x_{2}(t)
\end{array}\right]=\left[\begin{array}{l}
i_{d}(t) \\
i_{q}(t)
\end{array}\right],\left[\begin{array}{l}
u_{1} \\
u_{2}
\end{array}\right]=\left[\begin{array}{l}
p_{d}(t) \\
p_{q}(t)
\end{array}\right] .
$$

When designing a current controller, $V_{d c}$ is assumed to be constant since the inductor current in electrical power converters including AC/DC converters is much faster than the capacitor voltage [28]. Besides, the $\mathrm{d}-\mathrm{q}$ component of the AC subgrid voltage are considered as measurable parameters since the point of common coupling of the IC to the AC subgrid could be defined certainly, and in this paper $E_{d}$ and $E_{q}$ are given as:

$$
E_{d}=E_{a c}, E_{q}=0,
$$

where $E_{a c}$ is the AC subgrid voltage magnitude.

Hence, Equation (19) can be rewritten as:

$$
\dot{x}(t)=A x(t)+B(N u(t)+d),
$$

where:

$$
A=\left[\begin{array}{cc}
-\frac{R_{f}}{L_{f}} & \omega \\
-\omega & -\frac{R_{f}}{L_{f}}
\end{array}\right], B=\left[\begin{array}{cc}
\frac{1}{L_{f}} & 0 \\
0 & \frac{1}{L_{f}}
\end{array}\right], N=-\frac{V_{d c}}{2}, d=\left[\begin{array}{c}
E_{d}(t) \\
E_{q}(t)
\end{array}\right]=\left[\begin{array}{c}
E_{a c} \\
0
\end{array}\right] .
$$

The IC state space model can be reformulated to remove $d$ by solving the following equations:

$$
\begin{gathered}
u(t)=-\frac{d}{N}+u_{m}(t), \\
\dot{x}(t)=A x(t)+B N u_{m}(t) .
\end{gathered}
$$

Note that since $d$ is available, it can be used in the control, which is in sharp contrast to the grid tied inverter in which $\mathrm{d}$ is not measurable and servers as harmonic disturbances in general. 
It turns out that the IC state space model in the rectifier mode can be rewritten as:

$$
\left[\begin{array}{c}
\dot{x_{1}}(t) \\
\dot{x_{2}}(t)
\end{array}\right]=\left[\begin{array}{cc}
-\frac{R_{f}}{L_{f}} & \omega \\
-\omega & -\frac{R_{f}}{L_{f}}
\end{array}\right]\left[\begin{array}{l}
x_{1}(t) \\
x_{2}(t)
\end{array}\right]+\left[\begin{array}{cc}
\frac{N}{L_{f}} & 0 \\
0 & \frac{N}{L_{f}}
\end{array}\right]\left[\begin{array}{l}
u_{m 1}(t) \\
u_{m 2}(t)
\end{array}\right]
$$

In order to eliminate the steady state error, an integral control needs to be used in the control scheme. By adding this controller, the control output is expected to achieve the offset-free tracking. The auxiliary state $x_{I}=\left[\begin{array}{l}x_{I 1} \\ x_{I 2}\end{array}\right]$ satisfies:

$$
\dot{x_{I}}=r-y=r-C x, \quad x_{I}(0)=0 .
$$

In this equation, the desired reference $r$ denotes the current reference $i_{d}{ }^{*}$ and $i_{q}{ }^{*}$, which is generated by IC power reference after the droop control scheme. Thus, the augmented model for the controller design becomes:

$$
\left[\begin{array}{l}
\dot{x_{1}}(t) \\
\dot{x_{2}}(t) \\
\dot{x}_{11}(t) \\
\dot{x_{12}}(t)
\end{array}\right]=\left[\begin{array}{cccc}
-R_{f} / L_{f} & \omega & 0 & 0 \\
-\omega & -R_{f} / L_{f} & 0 & 0 \\
-1 & 0 & 0 & 0 \\
0 & -1 & 0 & 0
\end{array}\right]\left[\begin{array}{l}
x_{1}(t) \\
x_{2}(t) \\
x_{11}(t) \\
x_{12}(t)
\end{array}\right]+\left[\begin{array}{cc}
N / L_{f} & 0 \\
0 & N / L_{f} \\
0 & 0 \\
0 & 0
\end{array}\right]\left[\begin{array}{l}
u_{m 1}(t) \\
u_{m 2}(t)
\end{array}\right]+\left[\begin{array}{c}
0 \\
0 \\
i_{d}^{*}(t) \\
\dot{i}_{q^{*}}(t)
\end{array}\right] .
$$

While in the inverter mode, the power flows back from DC to AC as follows:

$$
\begin{aligned}
& \frac{d i_{d}(t)}{d t}=-\frac{R_{f}}{L_{f}} i_{d}(t)+\omega i_{q}(t)+\frac{V_{d c}(t)}{2 L_{f}} p_{d}(t)-\frac{E_{d}(t)}{L_{f}}, \\
& \frac{d i_{q}(t)}{d t}=-\frac{R_{f}}{L_{f}} i_{q}(t)-\omega i_{d}(t)+\frac{V_{d d}(t)}{2 L_{f}} p_{q}(t)-\frac{E_{q}(t)}{L_{f}},
\end{aligned}
$$

so the IC state space model changes into:

$$
\begin{gathered}
{\left[\begin{array}{c}
\dot{x}_{1}(t) \\
\dot{x}_{2}(t) \\
x_{I 1}(t) \\
\dot{x}_{I 2}(t)
\end{array}\right]=\left[\begin{array}{cccc}
-R_{f} / L_{f} & \omega & 0 & 0 \\
-\omega & -R_{f} / L_{f} & 0 & 0 \\
-1 & 0 & 0 & 0 \\
0 & -1 & 0 & 0
\end{array}\right]\left[\begin{array}{l}
x_{1}(t) \\
x_{2}(t) \\
x_{I 1}(t) \\
x_{I 2}(t)
\end{array}\right]+\left[\begin{array}{cc}
-N / L_{f} & 0 \\
0 & -N / L_{f} \\
0 & 0 \\
0 & 0
\end{array}\right]\left[\begin{array}{l}
u_{m 1}(t) \\
u_{m 2}(t)
\end{array}\right]+\left[\begin{array}{c}
0 \\
0 \\
i_{d^{*}}(t) \\
\dot{q}_{q}^{*}(t)
\end{array}\right] .} \\
\dot{\boldsymbol{x}}(t)=\boldsymbol{A x}(t)+\boldsymbol{B N} \boldsymbol{u}_{\boldsymbol{m}}(t)
\end{gathered}
$$

The quadratic performance cost function of the LQR is derived by:

$$
J=\int_{0}^{\infty}\left[x(t)^{T} Q x(t)+u_{m}(t)^{T} R u_{m}(t)\right] d t,
$$

where $Q$ is a symmetric positive semi-definite matrix and $R$ is a symmetric positive definite matrix.

The minimum cost is obtained by the following feedback control law:

$$
u_{m}(t)=-K_{L Q R} x(t),
$$

where the gain $K_{L Q R}$ is given by:

$$
K_{L Q R}=R^{-1} B^{T} P=\left[\begin{array}{ll}
K_{o} & K_{I}
\end{array}\right],
$$

and $P$ is a positive definite and symmetric matrix, derived by solving the Algebraic Riccati equation (ARE) as follows:

$$
\boldsymbol{A}^{T} P+P A+Q-P B R^{-1} B^{T} P=0 .
$$


In order to improve transient and robust performance, the regulator is modified with a prescribed degree of stability $-\alpha$ shift [29]. The dynamic system with this improved controller is defined as:

$$
\hat{x}(t)=(A+\alpha I) \hat{x}(t)+B N \hat{u}_{m}(t) .
$$

Thus the corresponding LQR gain becomes:

$$
K_{L Q R_{\alpha}}=R^{-1} B^{T} P_{\alpha} .
$$

$P_{\alpha}$ represents the solution of the modified ARE depending on $\alpha$, so Equation (36) becomes:

$$
(\boldsymbol{A}+\alpha I)^{T} P_{\alpha}+P_{\alpha}(\boldsymbol{A}+\alpha I)+Q-P_{\alpha} B R^{-1} B^{T} P_{\alpha}=0 .
$$

Note that there are three tuning parameters $(\alpha, Q, R)$ in the proposed controller. $\alpha$ affects on the decaying rate of the responses and robustness of the system, $Q$ determines behavior of the responses, and $R$ does amount of the used control input.

\section{Results and Discussion}

Three scenarios are tested to show the performance of the proposed control strategy in critical condition of the system operation as described in Table 1. Similar simulations were done separately by replacing the LQR by PI controller for the IC current tracking. Both control performances are compared and analyzed based on IC active and reactive powers, AC subgrid frequency, and DC subgrid voltage. After obtaining the gain parameters of the controllers in Matlab, the simulation of the system operation of the hybrid microgrid was done using PSCAD/EMTDC.

For simulation, the following control parameters are used:

$$
\alpha=14, Q=\left[\begin{array}{llll}
1 & 0 & 0 & 0 \\
0 & 1 & 0 & 0 \\
0 & 0 & 1 & 0 \\
0 & 0 & 0 & 1
\end{array}\right], R=\left[\begin{array}{cc}
0.001 & 0 \\
0 & 0.001
\end{array}\right]
$$

The resulting LQR feedback gain is given by $K_{L Q R_{\alpha}}=\left[\begin{array}{cccc}-33.11 & 0 & 902.12 & 422.67 \\ 0 & -33.11 & -422.67 & 902.12\end{array}\right]$ which is used for the reference tracking of the IC current. As comparison, PI controller is employed with $K_{p}=10$ and $K_{i}=10,000$. In this paper the minimum SOC level is $20 \%$, while the maximum level is $80 \%$.

Table 1. Scenarios for the simulation of hybrid AC/DC microgrid operation.

\begin{tabular}{ccccccc}
\hline \multirow{2}{*}{ Scenario } & \multirow{2}{*}{ Disturbance } & Transient & \multicolumn{2}{c}{ Operation Mode } & \multicolumn{2}{c}{ Operating Point } \\
\cline { 4 - 6 } & & Time & Before Transient & After Transient & Before Transient & After Transient \\
\hline I & Operation mode transition & $15 \mathrm{~s}$ & Grid-connected & Stand-alone & Maximum & Maximum \\
II & AC load increase & $10 \mathrm{~s}$ & Stand-alone & Stand-alone & Normal & Maximum \\
III & DC load increase & $10 \mathrm{~s}$ & Stand-alone & Stand-alone & Normal & Normal \\
\hline
\end{tabular}

\subsection{Operation Mode Transition from Grid-Connected to Stand-Alone Hybrid Microgrid}

In the first scenario, the hybrid microgrid was connected to the utility grid and the system was operated in its maximum loading point, $137 \mathrm{~kW}, 26 \mathrm{kVAR}$ in AC subgrid and $22 \mathrm{~kW}$ in DC subgrid. In order to supply AC load demand, AC subgrid sources, i.e., diesel generator set and wind turbine shared the output power with the utility grid. Diesel generator set provided $91 \mathrm{~kW}$ and $28 \mathrm{kVAR}$, while wind turbine produced $18 \mathrm{~kW}$ and consumed $12 \mathrm{kVAR}$. Utility grid supported power $30 \mathrm{~kW}$ and $10 \mathrm{kVAR}$ only to AC subgrid since DC load was already satisfied by the PV system in DC subgrid, around $22 \mathrm{~kW}$. 
At $t=15 \mathrm{~s}$, system operation changed into stand-alone mode. Power support from utility grid was gone and the sources in hybrid microgrid needed to increase its output power to satisfy the load demand. The droop control of diesel generator increased the output power around $10 \mathrm{~kW}$ and $10 \mathrm{kVAR}$, and the system frequency was still decreasing as there was not enough supply in AC subgrid. At that time, battery SOC was enough to charge or discharge power to DC subgrid. It turns out that the gain parameter of $\frac{1}{R_{p, d c}}$ was set to zero and IC droop control generated the active power reference based on the frequency deviation in AC system. The decreasing frequency in AC subgrid caused the IC controller drawing active power from DC subgrid to be injected to AC subgrid. Battery converter sensed the voltage in DC subgrid decreasing as IC kept drawing power from DC subgrid. Then battery discharged power up to the maximum power injection of IC, $20 \mathrm{~kW}$, which was in proportion to the voltage decrease in DC subgrid. Meanwhile the reactive power increase in AC subgrid was already fulfilled by diesel generator set so IC did not inject reactive power to AC subgrid. Figures 12-14 show the active power and reactive power flows in both subgrids for the first scenario.

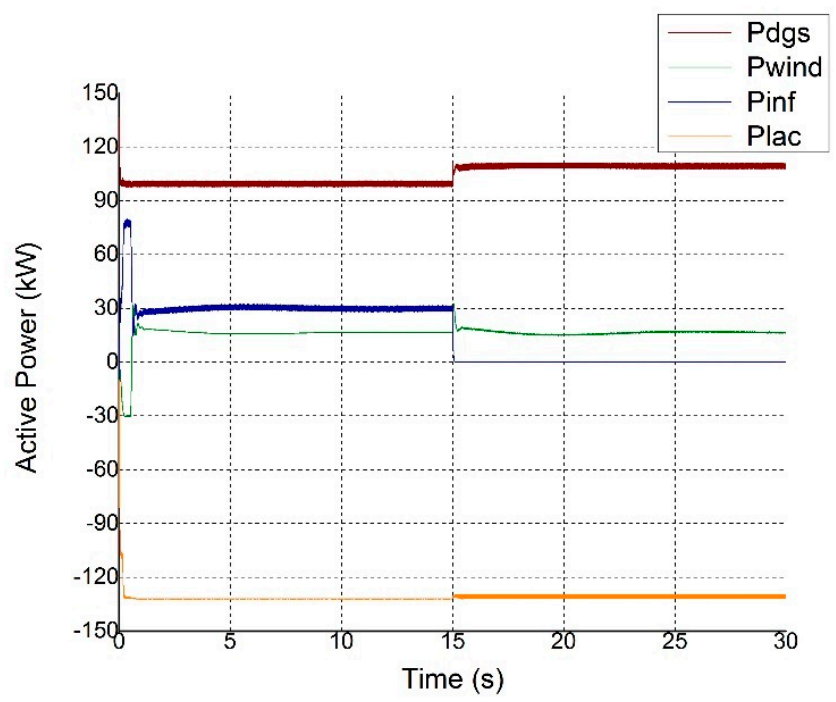

Figure 12. Active power flow in AC subgrid when the operation mode changed to stand-alone.

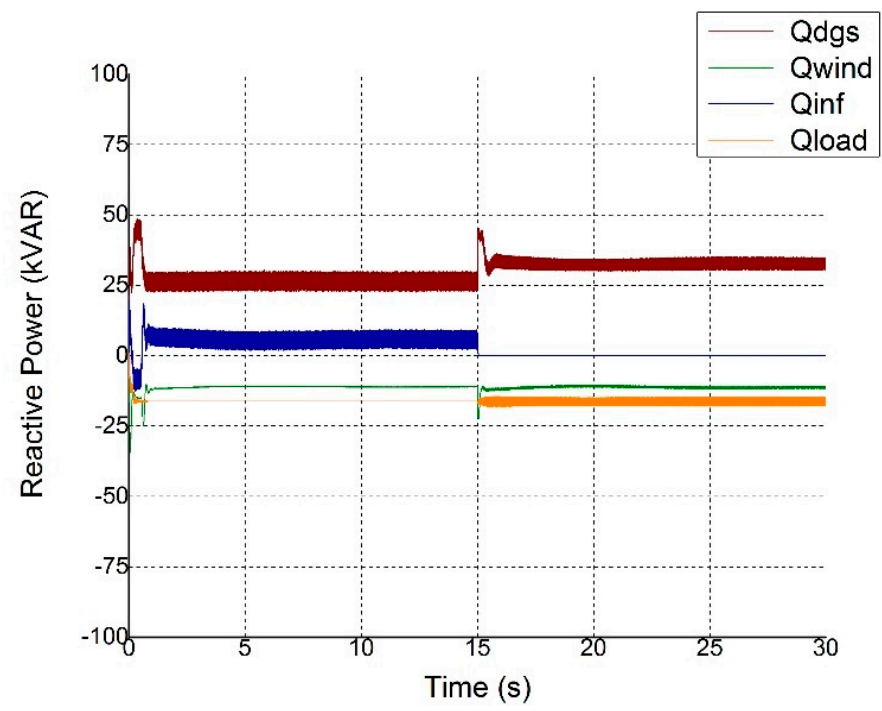

Figure 13. Reactive power flow in AC subgrid when the operation mode changed to stand-alone. 


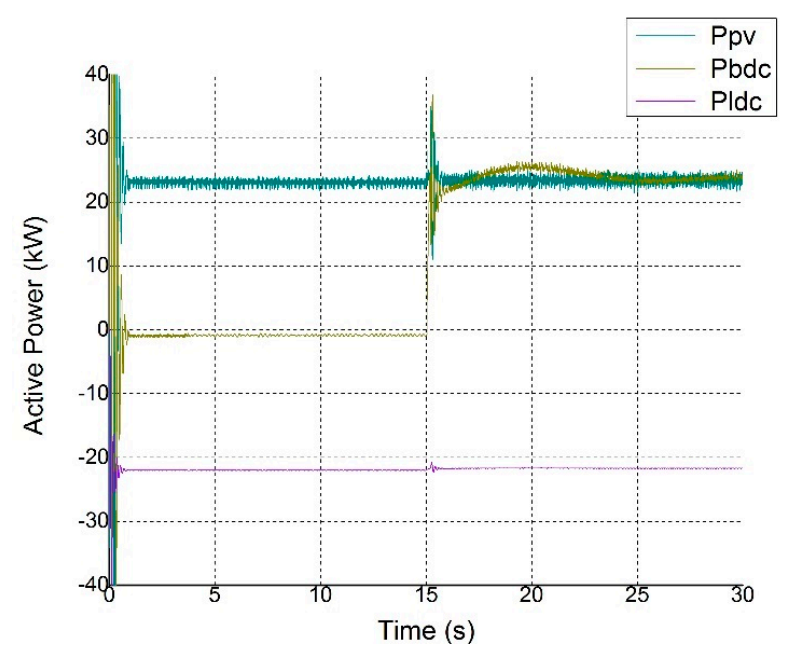

Figure 14. Active power flow in DC subgrid when the operation mode changed to stand-alone.

Figure 15 shows the comparison of control performance between PI and LQR controllers in view of IC power injection, AC subgrid frequency, and DC subgrid voltage. After the operation mode changed into stand-alone mode, the injection power by IC using LQR with exponential weighting presented better transient response compared to PI. The controller was able to transfer the power rapidly and smoothly from DC subgrid to AC subgrid during the operation mode transition. The frequency response by LQR was stabilized at $58.5 \mathrm{~Hz}$ or within the allowable operating range. Because the one with PI controller converges to $57.5 \mathrm{~Hz}$, lower than the minimum operating range, it leads to frequency instability. In this case, then, further remedial actions such as load shedding need to be taken to restore frequency stability. It implies that LQR works well over wider operation conditions robustly.

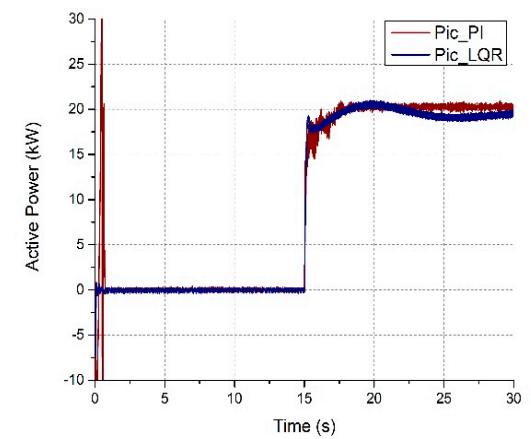

(a)

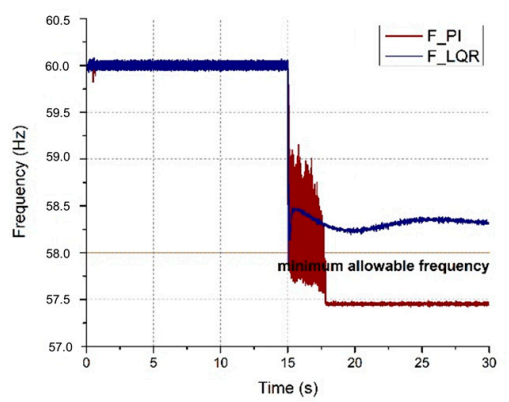

(c)

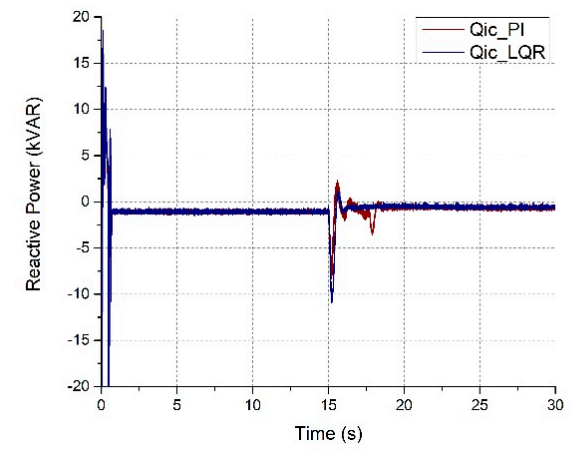

(b)

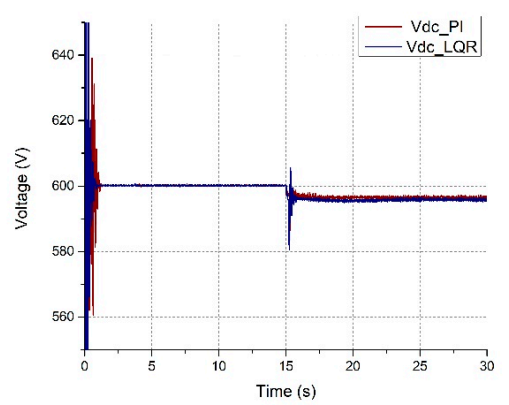

(d)

Figure 15. Comparison of system responses with PI and LQR controllers when the operation mode changed to stand-alone at $15 \mathrm{~s}$; (a) active power injection of IC; (b) reactive power injection of IC; (c) AC subgrid frequency and (d) DC subgrid voltage. 
In the DC subgrid, the DC voltage response for both controllers was maintained in $595 \mathrm{~V}$ due to the coordination control with the battery converter. Figure $15 \mathrm{~d}$ shows that the DC voltage transient was higher for IC with LQR since during transition from grid-connected to stand-alone hybrid microgrid, the generated power transfer of IC with LQR has higher transient compared to the one with PI controller. Figure 16 shows the comparison of control performance between PI and LQR in view of current tracking, voltage at point of common coupling (PCC) to AC subgrid in $d-q$ axis, and the closed loop output. As shown in Figure 16 (1), current tracking performance of LQR was more stable compared to PI controller. And as can be seen in Figures 15 and 16, the LQR with exponential weighting had higher transient compared to PI controller during the operation mode transition. However, even though the transient was high, it was more stable compared to the PI controller response. So did the steady state, IC with LQR was more stable compared to the one with PI controller.

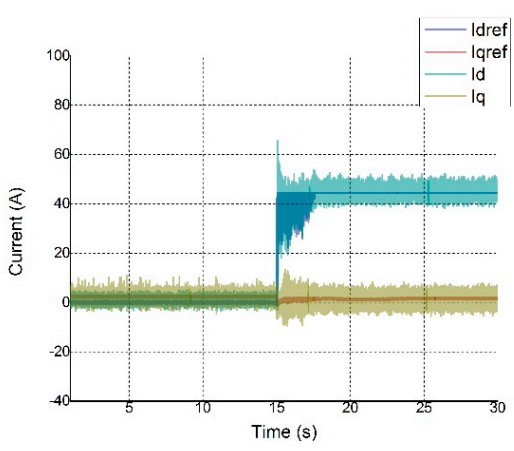

(a)

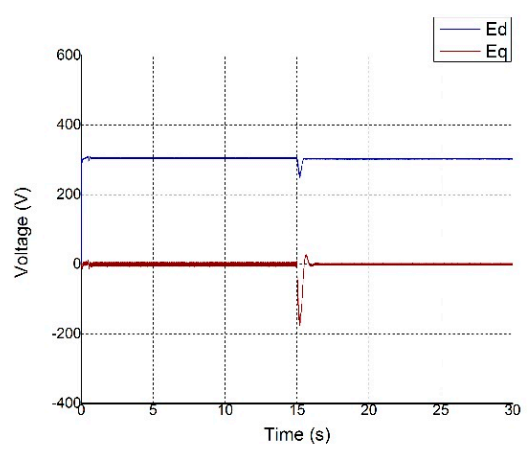

(c)

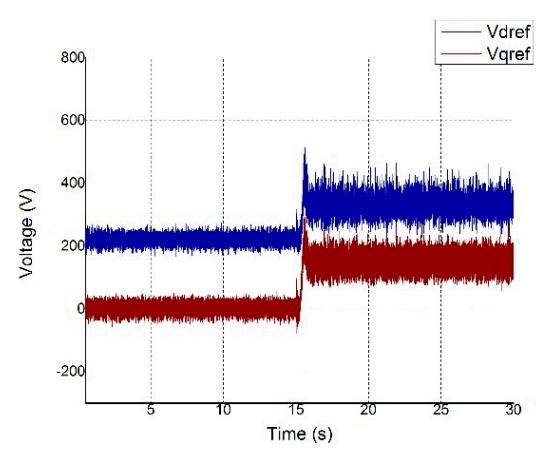

(e)

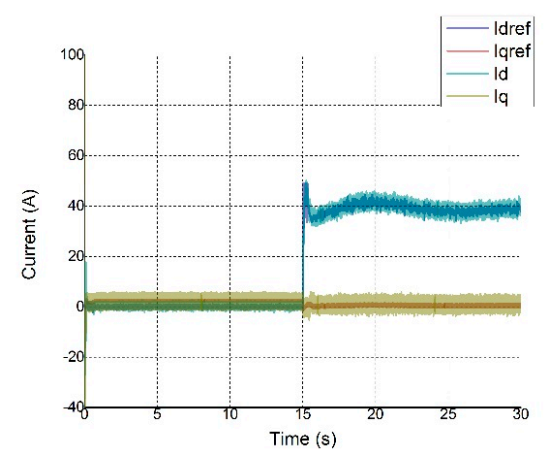

(b)

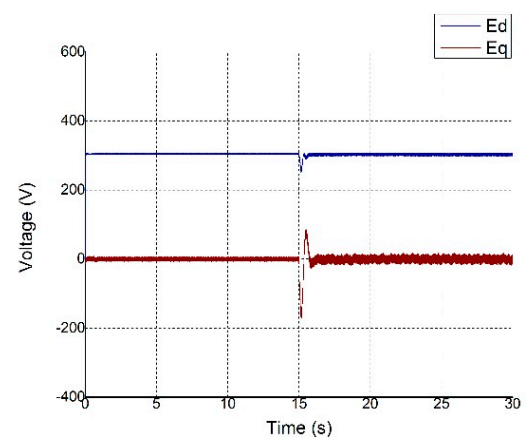

(d)

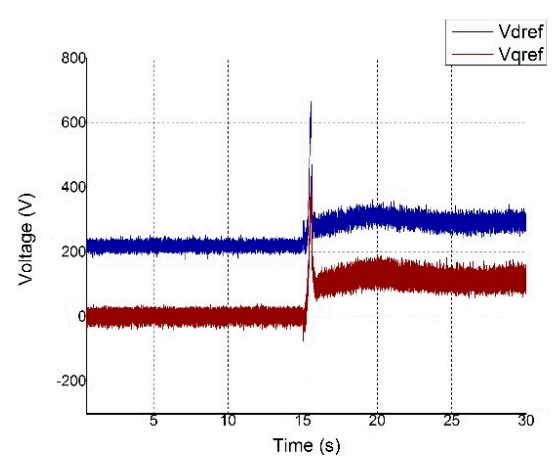

(f)

Figure 16. Control performance comparison between PI and LQR in the first scenario (1) current tracking (2) $d$-q frame voltage at point of common coupling (PCC) to AC subgrid (3) closed loop output. (a) PI controller; (b) LQR; (c) PI controller; (d) LQR; (e) PI controller; (f) LQR. 


\subsection{AC Load Increase with Battery Support}

In the second scenario, the hybrid microgrid was operated in stand-alone mode. At the beginning, system was operated in normal operating point, where AC load was $105 \mathrm{~kW}$ and $23 \mathrm{kVAR}$, while DC load was $22 \mathrm{~kW}$. After $10 \mathrm{~s}$, AC load increased to $130 \mathrm{~kW}$. Battery had enough SOC to charge or discharge power, so the gain parameter $\frac{1}{R_{p, d c}}$ was set to zero. After transient happened, AC subgrid frequency decreased because the load increased to the maximum loading point. IC sensed the frequency deviation and the droop control generated some amount of power reference to be injected to the AC subgrid. BESS in DC subgrid discharged $20 \mathrm{~kW}$ to satisfy the AC load demand, which was transferred through the IC. Reactive power in AC subgrid was supplied by the diesel generator set. Figures 17-19 show the active and reactive power flows in both subgrids for the second scenario.

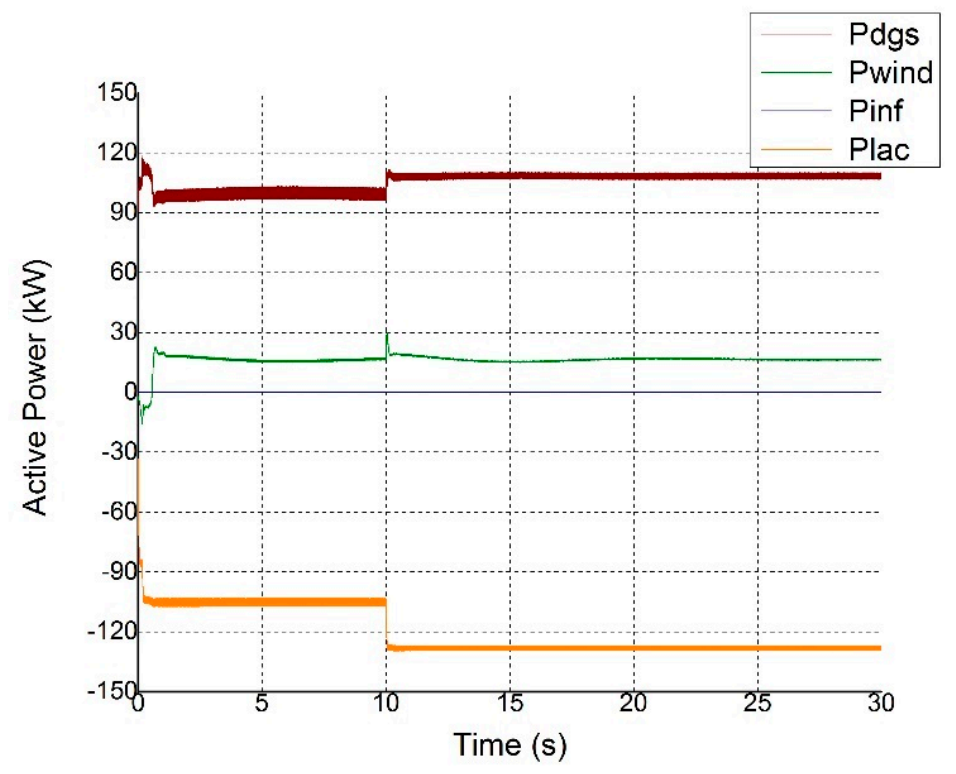

Figure 17. Active power flow in AC subgrid when AC load increased to maximum loading point.

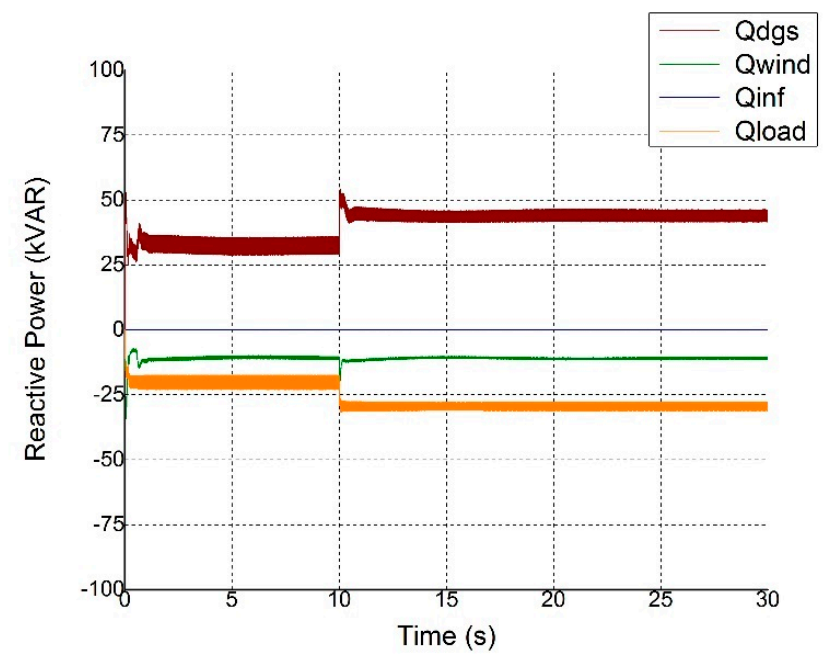

Figure 18. Reactive power flow in AC subgrid when AC load increased to maximum loading point. 


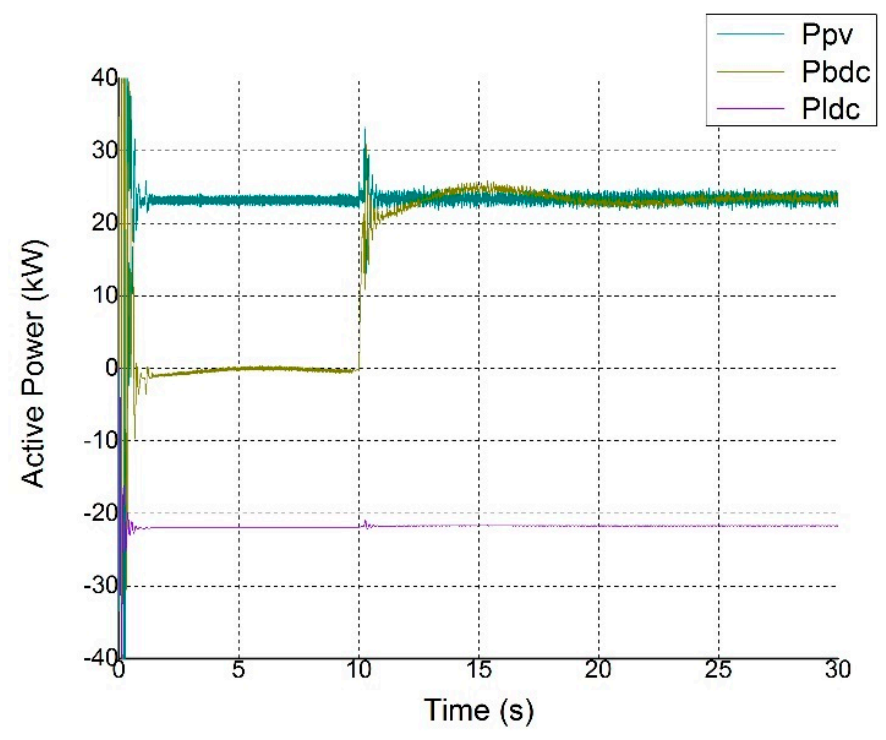

Figure 19. Active power flow in DC subgrid when AC load increased to maximum loading point.

Figure 20a,b show the IC active and reactive power injection where the performance of IC with LQR based current control is compared to the one with PI controller. After the AC load increased, the injection power by IC using LQR with exponential weighting was more stable compared to the one with PI controller. Power transfer was done rapidly from DC subgrid to AC subgrid, and frequency response by LQR was stabilized at $58.5 \mathrm{~Hz}$ or within the allowable operating range as shown in Figure 20c. Meanwhile, frequency response by PI controller was around $57.5 \mathrm{~Hz}$ or below the minimum operating range. As in Figure 20d, DC voltage response was still maintained well, around 595 V, because of the coordinated control with the battery converter.

Figure 21 shows the control performance comparison between PI and LQR in view of current tracking, voltage at point of common coupling (PCC) to AC subgrid in $d-q$ axis, and the closed loop output. The current tracking performance of LQR with exponential weighting was better and more stable compared to PI controller. For IC with LQR controller, the transient response when the load increased was different with the previous scenario which the transient was caused by the change of the operation mode. In this scenario, the transient of IC with LQR was lower and more stable compared to the one with LQR in previous scenario as well as the one with PI controller in this scenario. The steady state of LQR was also more stable than PI controller.

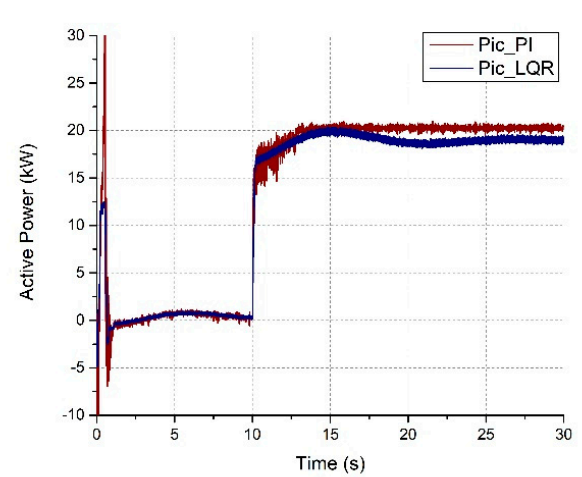

(a)

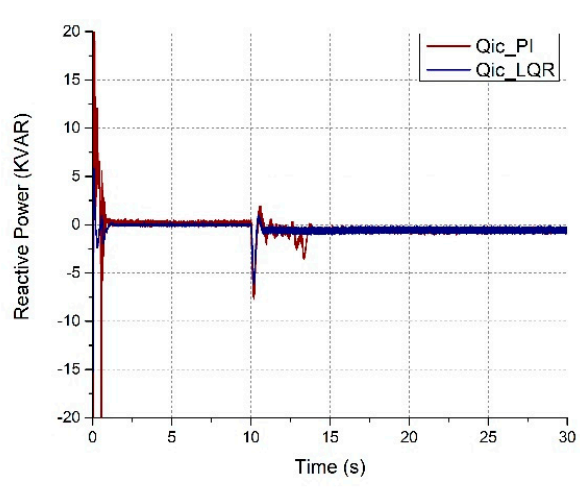

(b)

Figure 20. Cont. 


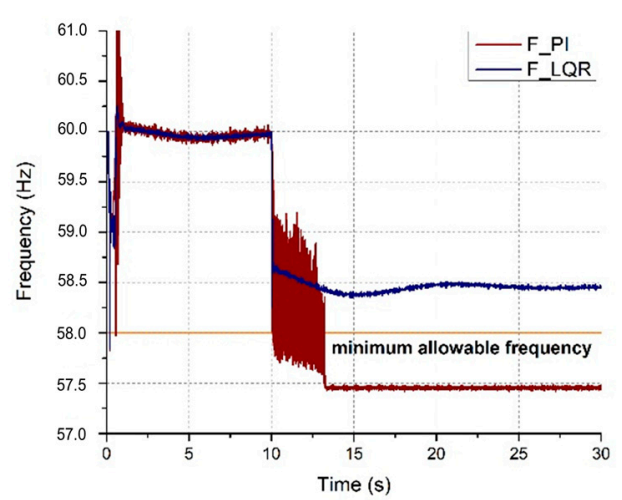

(c)

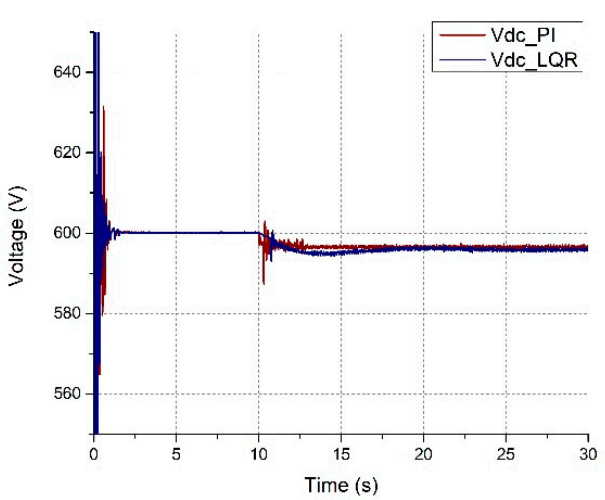

(d)

Figure 20. Comparison of system responses with PI and LQR controllers when AC load increased to maximum loading point at $10 \mathrm{~s}$; (a) active power injection of IC; (b) reactive power injection of IC; (c) AC subgrid frequency and (d) DC subgrid voltage.

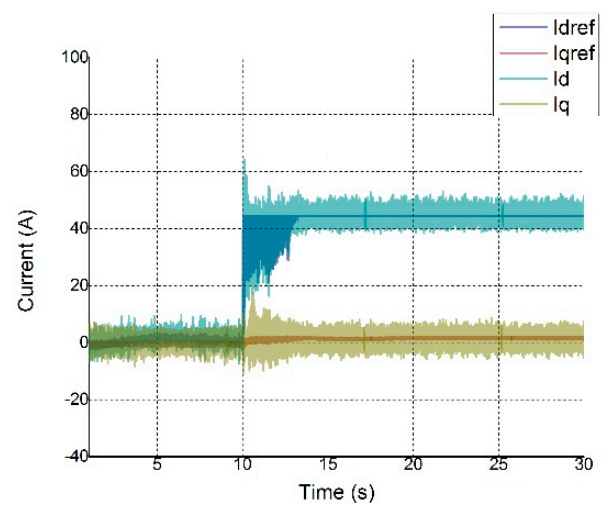

(a)

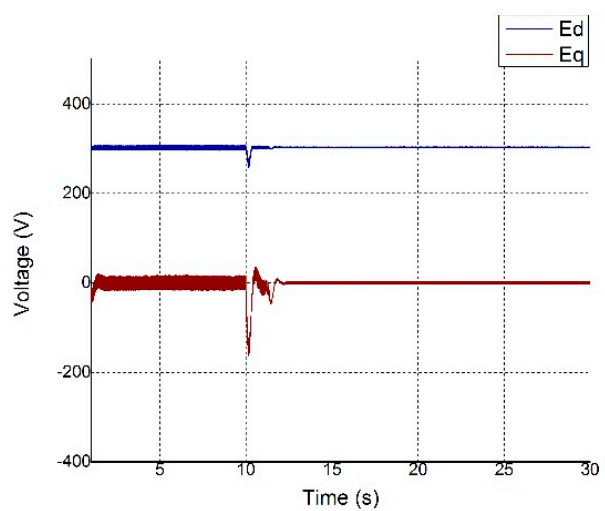

(c)

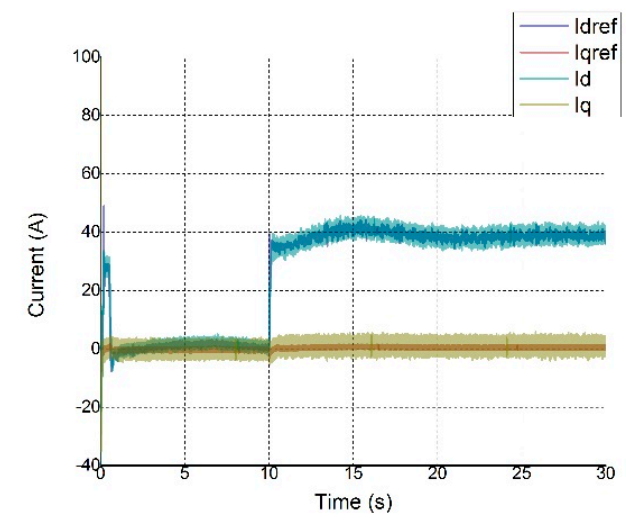

(b)

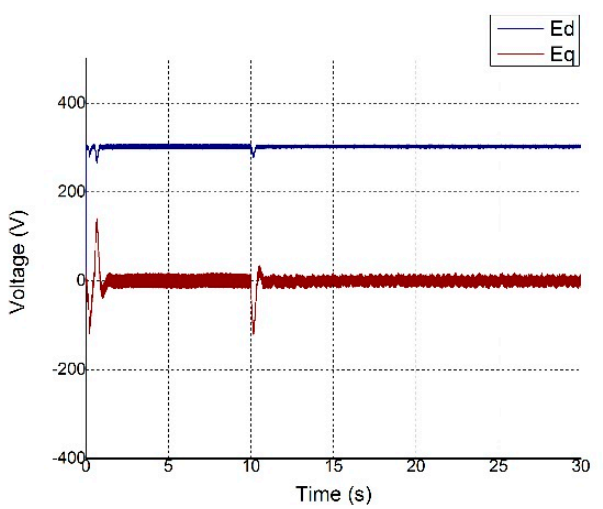

(d)

Figure 21. Cont. 


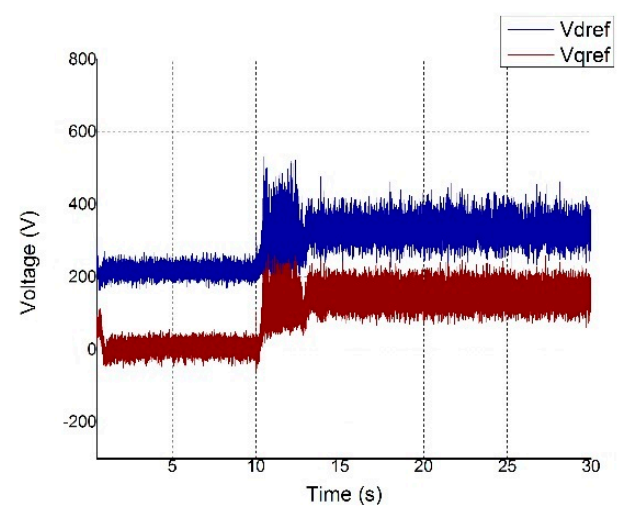

(e)

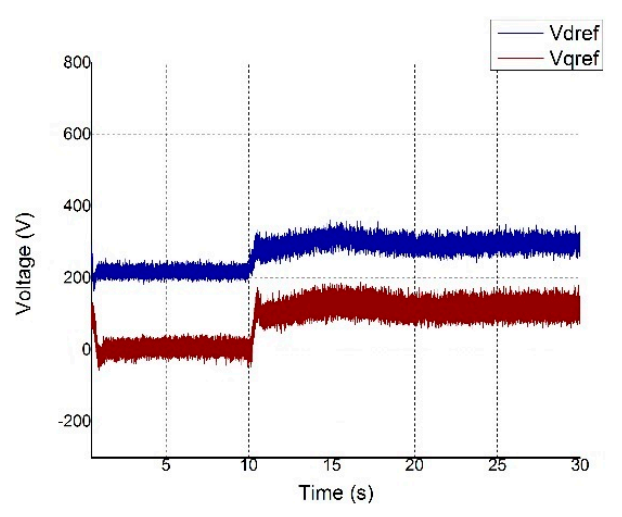

$(\mathbf{f})$

Figure 21. Control performance comparison between PI and LQR in the second scenario (1) current tracking (2) $d-q$ frame voltage at point of common coupling (PCC) to AC subgrid (3) closed loop output. (a) PI controller; (b) LQR; (c) PI controller; (d) LQR; (e) PI controller; (f) LQR.

Using the same scenario, the IC with LCL filter $\left(\mathrm{L}_{1}=5 \mathrm{mH}, \mathrm{C}=10 \mu \mathrm{F}, \mathrm{L}_{2}=5 \mathrm{mH}\right)$ has been simulated without changing the state space model. By deploying the same LQR gains as in the proposed one with $\mathrm{L}$ filter, the controller outputs and system responses are almost the same.

\subsection{Load Increase without Battery Support}

In the third scenario, hybrid microgrid operation was started as in the second scenario, and the DC load increased around $10 \mathrm{~kW}$ at $t=10 \mathrm{~s}$. At that time, battery does not have enough SOC to discharge power to DC load demand. Gain parameter $\frac{1}{R_{p, d c}}$ was set to $\frac{\Delta P_{d c}}{\Delta V_{d c}}$ and IC droop control managed proportional power sharing between both subgrids, thus IC only injected $8 \mathrm{~kW}$ to DC subgrid or $80 \%$ of deficient demand in DC subgrid. IC did not draw $100 \%$ power deficient of DC subgrid since AC subgrid did not have enough surplus power to support DC subgrid. By managing proportional power sharing between both subgrids through IC, the security and stability of the whole system operation were maintained well. Figures 22-24 show the active power and reactive power flows in both subgrids for the third scenario.

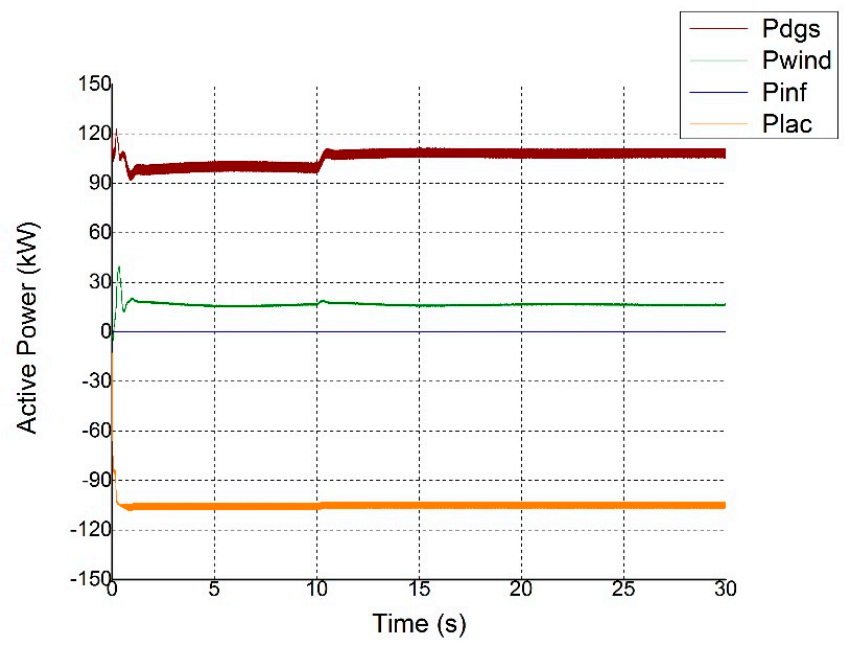

Figure 22. Active power flow in AC subgrid when the DC load was increased and there was no battery support. 


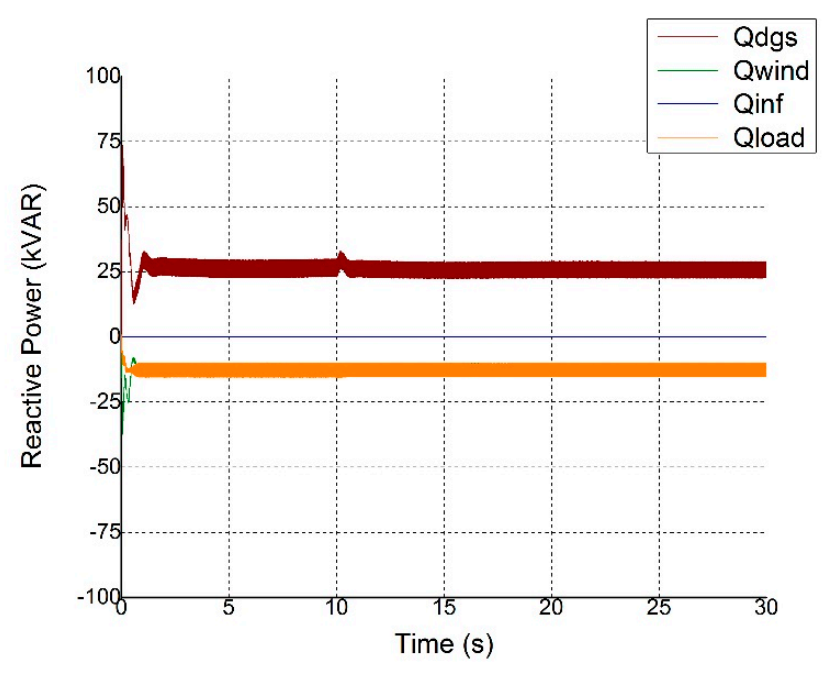

Figure 23. Reactive power flow in AC subgrid when the DC load was increased and there was no battery support.

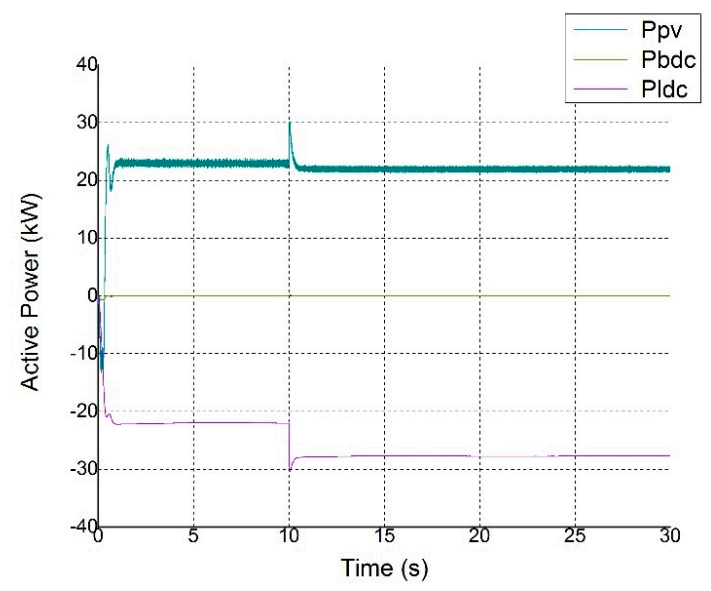

Figure 24. Active power flow in DC subgrid when the DC load was increased and there was no battery support.

Figure 25 shows the IC power injection, AC subgrid frequency, and DC subgrid voltage in the third scenario where the performance of IC with LQR based current control is compared to the one with the PI controller. After the DC load increased, the injection power by both controllers was transferred rapidly from $\mathrm{AC}$ subgrid. The control performances of both controllers resulted AC subgrid frequency maintained in $59.4 \mathrm{~Hz}$ after some amount of power in AC subgrid was transferred to DC subgrid, as well as DC subgrid voltage was maintained in $560 \mathrm{~V}$. It shows that while system is operated in normal operating point, control performance of both controllers are almost similar.

The control performance comparison between PI and LQR in view of current tracking, voltage at point of common coupling (PCC) to AC subgrid in $d-q$ axis, and the closed loop output are shown in Figure 26. There is no significant differences among both controllers since the system was operated in normal operating point. The transient responses and the steady states are almost similar as well. 


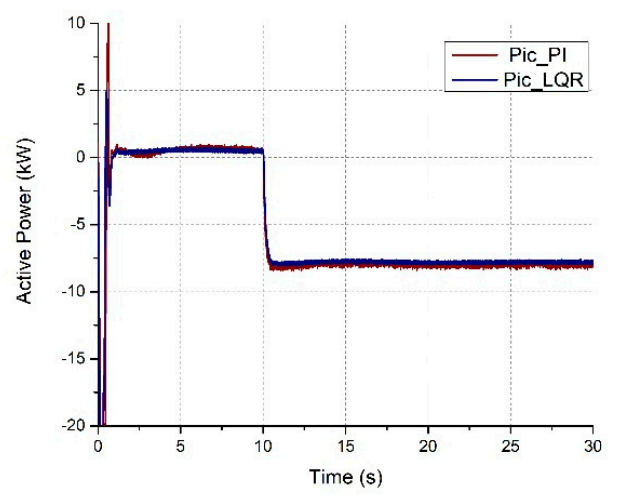

(a)

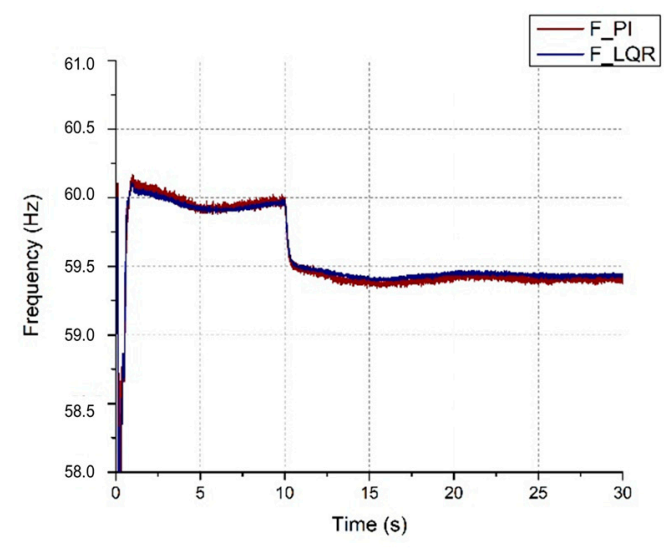

(c)

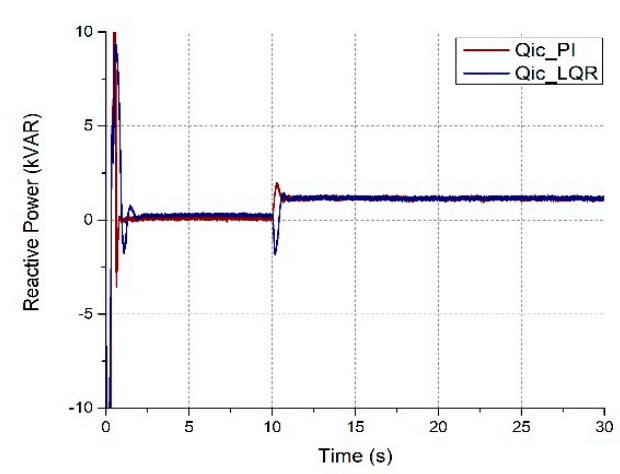

(b)

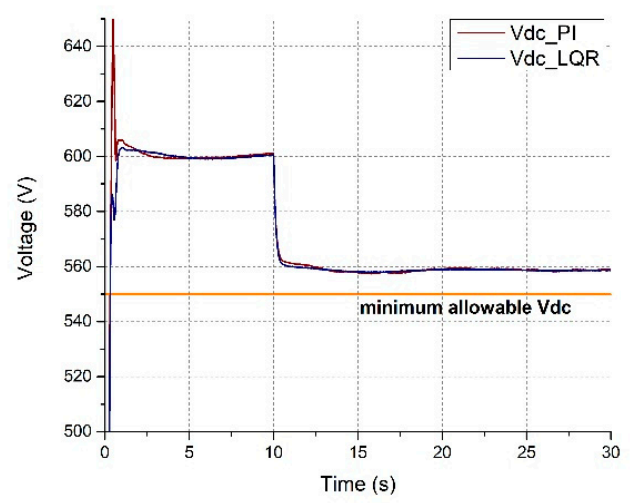

(d)

Figure 25. Comparison of system responses with PI and LQR controllers LQR when DC load increased and there was no battery support at $10 \mathrm{~s}$; (a) active power injection of IC; (b) reactive power injection of IC; (c) AC subgrid frequency and (d) DC subgrid voltage.

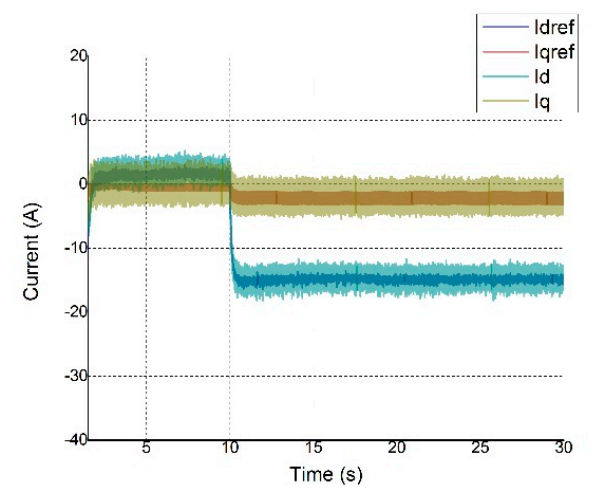

(a)

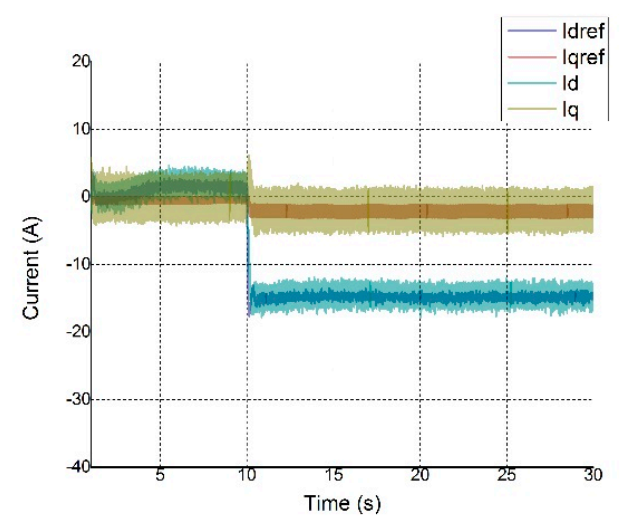

(b)

Figure 26. Cont. 


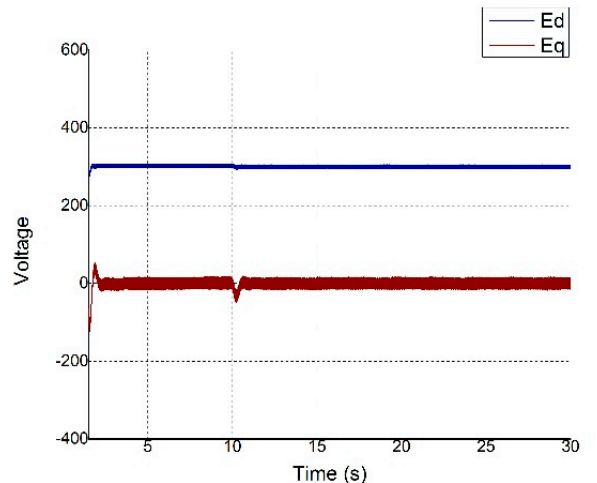

(c)

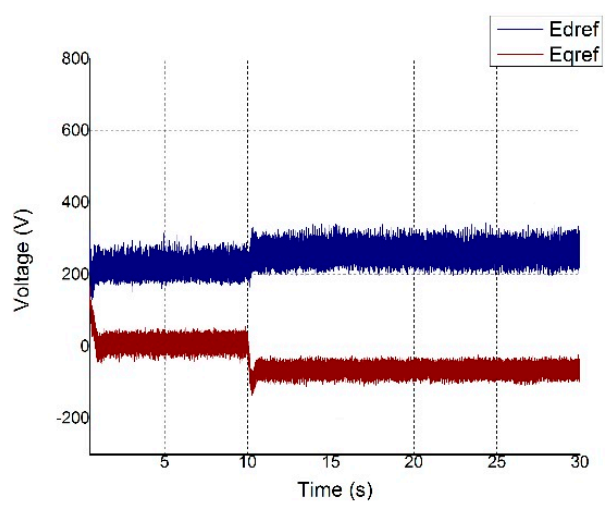

(e)

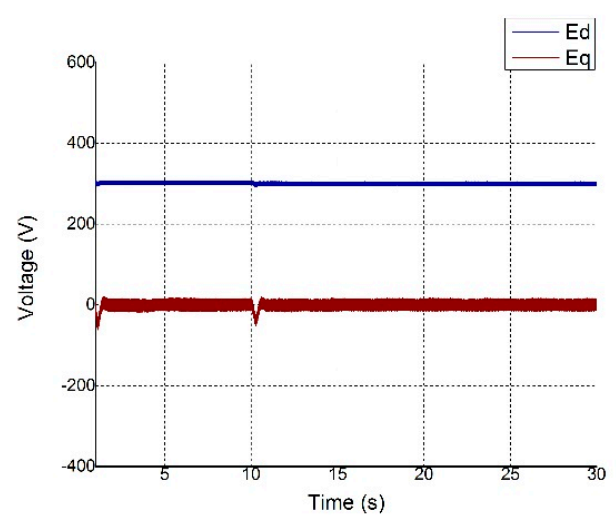

(d)

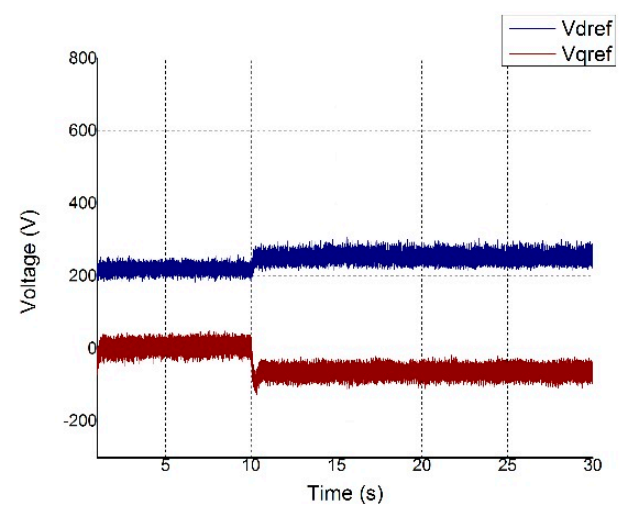

(f)

Figure 26. Control performance comparison between PI and LQR in the third scenario (1) current tracking (2) $d-q$ frame voltage at point of common coupling (PCC) to AC subgrid (3) closed loop output. (a) PI controller; (b) LQR; (c) PI controller; (d) LQR; (e) PI controller; (f) LQR.

From simulation results above, the comparison of control performance between LQR and PI controllers can be summarized as indicated in Table 2.

Table 2. Comparison of control performance between LQR and PI controllers.

\begin{tabular}{cll}
\hline No & \multicolumn{1}{c}{ LQR with Exponential Weighting } & \multicolumn{1}{c}{ PI Controller } \\
\hline 1 & $\begin{array}{l}\text { Power is transferred between subgrids rapidly } \\
\text { and stably }\end{array}$ & $\begin{array}{l}\text { Power is transferred between subgrids rapidly } \\
\text { but not as stable as LQR controller }\end{array}$ \\
\hline 2 & $\begin{array}{l}\text { The hybrid microgrid operates robustly against } \\
\text { various operation conditions }\end{array}$ & $\begin{array}{l}\text { The hybrid microgrid operation is limited in } \\
\text { maximum loading point }\end{array}$ \\
\hline 3 & $\begin{array}{l}\text { During transition mode from grid connected to } \\
\text { stand-alone operation, the transient response is } \\
\text { high but smooth }\end{array}$ & $\begin{array}{l}\text { During transition mode from grid connected to } \\
\text { stand-alone operation, the transient response is } \\
\text { low but not smooth }\end{array}$ \\
\hline 4 & Easy to adjust LQR parameters for MIMO systems & Hard to adjust PI parameters for MIMO systems \\
\hline
\end{tabular}

To implement the control scheme on an IC for hybrid microgrids, a DSP (Digital Signal Processor) or similar platform can be used. Since this platform needs a discrete-time controller, we need to check if the discrete-time version of the proposed controller works or not. To this end, we tested the discrete-time version of the proposed controller with the system in Equation (30) and a zero-holder. We obtained similar results. In view of this, we believe that the proposed controller can be used in real time application as well. 


\section{Conclusions}

In a hybrid AC/DC microgrid, IC control plays an important role for active power sharing between both subgrids in order to maintain secure system operation. In hybrid microgrid where the BESS is installed in one subgrid, coordinated control of IC and battery converter is required in order to maintain both systems more efficiently. From the simulations above, one can notice that the proposed control strategy is able to maintain the security of hybrid microgrid operation. The IC current control using LQR with exponential weighting shows better performance in sharing power between the subgrids in order to maintain the system security compared to the one with PI controller. By adding the exponential weighting to the LQR gain parameter, the controller works robustly particularly in maximum operating point. The proposed controller leads the power transfer to be carried out more rapidly from the under-loaded subgrid to the over-loaded one. Besides, the power flow is maintained more stably after transient happened. In other words, LQR with exponential weighting provides a robust control solution in various operating conditions of the hybrid AC/DC microgrid.

Acknowledgments: This work was supported by the Human Resources Development of the Korea Institute of Energy Technology Evaluation and Planning (KETEP) grant funded by the Ministry of Trade, Industry \& Energy of the Korea government (No. 20154030200720), and by Basic Science Research Program through the National Research Foundation of Korea (NRF) funded by the Ministry of Education (NRF-2015R1D1A1A0106 0588)

Author Contributions: Dwi R. Aryani surveyed the backgrounds of this research, designed the control strategies, and performed the simulations so as to show the benefits of the proposed method. Jung-Su Kim and Hwachang Song supervised and supported this study.

Conflicts of Interest: The authors declare no conflict of interest.

\section{Nomenclature}

$\Delta f$

$\Delta P_{d c}$

$\Delta V_{d c}$

$\omega$

$C$

$E_{a c}$

$E_{a b c}$

$E_{d}$

$E_{q}$

$f_{a c}$

$f_{m}$

$f_{\text {max }}$

$f_{\min }$

$f_{\text {min,ac }}$

$f_{\text {ref }}$

$i_{a b c}$

$I_{d}$

$I_{d, r e f}$

$i_{d c}$

$i_{L, d c}$

$I_{q}$

$I_{q, \text { ref }}$

$L_{f}$

$p_{a b c}$

$p_{d q}$

$P_{a c}$

$P_{d c}$

$P_{I C}$

$P_{l, d c}$

$P_{\max , a c}$

$P_{\max , d c}$

$P_{\text {net }}$

$P_{s, d c}$

frequency deviation on the AC subgrid

active power deviation on the DC subgrid

bus voltage deviation on the DC subgrid

grid angular frequency

DC link capacitance

AC subgrid voltage magnitude

three phase voltage at AC subgrid

$d$-axis AC subgrid voltage

$q$-axis AC subgrid voltage

AC microgrid frequency

measured frequency in AC subgrid

maximum allowable frequency in AC subgrid

minimum allowable frequency in AC subgrid

minimum allowable frequency in AC microgrid

reference of frequency in AC subgrid

current at AC side of IC

$d$-axis current at AC side of IC

reference of $d$-axis current at AC side of IC

current at DC side of IC

inductor current at DC side of IC

$q$-axis current at AC side of IC

reference of $q$-axis current at AC side of IC

filter inductance

gating signal of IC represented in three phase form

gating signal of IC represented in $d-q$ axis

active power generated by the droop control in AC microgrid

active power generated by the droop control in DC microgrid

active power reference of IC

active power of DC load

maximum active power of the AC droop control scheme

maximum active power of the DC droop control scheme

net active power in DC subgrid

active power of DC source 
$Q_{a c} \quad$ reactive power produced by the droop control in AC microgrid

$Q_{\text {IC }} \quad$ reactive power reference of IC

$Q_{\max , a c} \quad$ maximum reactive power of the AC droop control scheme

$R_{d c} \quad$ voltage-active power droop characteristic in DC microgrid

$R_{f} \quad$ filter resistance

$R_{p, a c} \quad$ frequency-active power droop characteristic in AC microgrid

$R_{p 1} \quad$ Frequency-active power droop characteristic of IC

$R_{p 2} \quad$ DC voltage-active power droop characteristic of IC

$R_{q} \quad$ AC voltage-reactive power droop characteristic of IC

$R_{q, a c} \quad$ voltage-reactive power droop characteristic in AC microgrid

$V_{a b c} \quad$ voltage at AC side of IC

$V_{a c} \quad$ measured AC voltage in AC microgrid

$V_{a c, m} \quad$ measured voltage in AC subgrid

$V_{a c, r e f} \quad$ reference voltage in AC subgrid

$V_{d} \quad d$-axis voltage reference at AC side of IC

$V_{d c} \quad$ measured voltage in DC microgrid

$V_{d c, m} \quad$ measured voltage in DC subgrid

$V_{d c, \max } \quad$ maximum allowable voltage in DC subgrid

$V_{d c, \text { min }} \quad$ minimum allowable voltage in DC subgrid

$V_{d c, \text { ref }} \quad$ reference of voltage in DC subgrid

$V_{\text {min,ac }} \quad$ minimum allowable voltage in AC microgrid

$V_{\min , d c} \quad$ minimum allowable voltage in DC microgrid

$V_{q} \quad q$-axis voltage reference at AC side of IC

\section{References}

1. Hatziargyriou, N. The Microgrid Concepts. In Microgrids Architectures and Control; Wiley: Chichester, UK, 2004; pp. 3-6.

2. Karavas, C.S.; Kyriakarakos, G.; Arvanitis, K.G.; Papadakis, G. A multi-agent decentralized energy management system based on distributed intelligence for the design and control of autonomous polygeneration microgrids. Energy Convers. Manag. 2015, 103, 166-179. [CrossRef]

3. Kuznetsova, E.; Li, Y.F.; Ruiz, C.; Zio, E. An integrated framework of agent-based modelling and robust optimization for microgrid energy management. Appl. Energy 2014, 129, 70-88. [CrossRef]

4. Raju, E.S.N.; Jain, T. Hybrid AC/DC Microgrid: An Overview. In Proceedings of the Fifth International Conference on Power and Energy Systems, Kathmandu, Nepal, 28-30 October 2013.

5. Nejabatkhah, F.; Li, Y.W. Overview of Power Management Strategies of Hybrid AC/DC Microgrid. IEEE Trans. Power Electron. 2015, 30, 7072-7089. [CrossRef]

6. Eajal, A.A.; El-Saadany, E.F.; Ponnambalam, K. Optimal power flow for converter-dominated AC/DC hybrid microgrids. In Proceedings of the 2017 IEEE International Conference on Industrial Technology (ICIT), Toronto, ON, Canada, 22-25 March 2017; pp. 603-608.

7. Tedesco, F.; Mariam, L.; Basu, M.; Casavola, A.; Conlon, M.F. Economic model predictive control-based strategies for cost-effective supervision of community microgrids considering battery lifetime. IEEE J. Emerg. Sel. Top. Power Electron. 2015, 3, 1067-1077. [CrossRef]

8. Lu, X.; Guerrero, J.M.; Sun, K.; Vasquez, J.C.; Teodorescu, R.; Huang, L. Hierarchical Control of Parallel AC-DC Converter Interfaces for Hybrid Microgrids. IEEE Trans. Smart Grid 2014, 5, 683-692. [CrossRef]

9. Guerrero, J.M.; Vasquez, J.C.; Matas, J.; de Vicuna, L.G.; Castilla, M. Hierarchical Control of Droop-Controlled AC and DC Microgrids-A General Approach toward Standardization. IEEE Trans. Ind. Electron. 2011, 58, 158-172. [CrossRef]

10. Eghtedarpour, N.; Farjah, E. Power Control and Management in a Hybrid AC/DC Microgrid. IEEE Trans. Smart Grid 2014, 5, 1494-1505. [CrossRef]

11. Loh, P.C.; Li, D.; Chai, Y.K.; Blaabjerg, F. Autonomous Operation of Hybrid Microgrid with AC and DC Subgrids. IEEE Trans. Power Electron. 2013, 28, 2214-2223. [CrossRef]

12. Aryani, D.R.; Song, H. Coordination Control Strategy for AC/DC Hybrid Microgrids in Stand-Alone Mode. Energies 2016, 9, 469. [CrossRef]

13. Alam, F.; Ashfaq, M.; Zaidi, S.S.; Memon, A.Y. Robust droop control design for a hybrid AC/DC microgrid. In Proceedings of the 2016 UKACC 11th International Conference on Control (CONTROL), Belfast, UK, 31 August-2 September 2016. 
14. Hu, W.; Chen, H.; Yang, X.; Xu, K.; Hu, P. Control strategy of the bi-directional converter for hybrid AC/DC microgrid. In Proceedings of the 2015 IEEE PES Asia-Pacific Power and Energy Engineering Conference (APPEEC), Brisbane, Australia, 15-18 November 2015.

15. Xing, P.; Fu, L.; Wang, G.; Ma, F.; Zhou, L.; Wang, Y. Control strategy of seamless operation mode switch for AC/DC hybrid microgrid. In Proceedings of the 2016 IEEE International Conference on Aircraft Utility Systems (AUS), Beijing, China, 10-12 October 2016; pp. 1030-1034.

16. Li, P.; Yan, S.; Yu, X.; Zhang, J. The Ho control method of bidirectional converter in hybrid AC/DC microgrid. In Proceedings of the 2016 IEEE Power and Energy Society General Meeting (PESGM), Boston, MA, USA, 17-21 July 2016.

17. Chettibi, N.; Mellit, A.; Sulligoi, G.; Pavan, A.M. Adaptive Neural Network-Based Control of a Hybrid AC/DC Microgrid. IEEE Trans. Smart Grid 2016, PP, 1-13. [CrossRef]

18. Xia, Y.; Peng, Y.; Yang, P.; Yu, M.; Wei, W. Distributed Coordination Control for Multiple Bidirectional Power Converters in a Hybrid AC/DC Microgrid. IEEE Trans. Power Electron. 2016, 32, 4949-4959. [CrossRef]

19. Xiao, H.; Luo, A.; Shuai, Z.; Jin, G.; Huang, Y. An Improved Control Method for Multiple Bidirectional Power Converters in Hybrid AC/DC Microgrid. IEEE Trans. Smart Grid 2016, 7, 340-347. [CrossRef]

20. Wang, X.; Sun, K.; Li, Y.; Nejabatkhah, F.; Mei, Y. Parallel operation of bi-directional interfacing converters in a hybrid AC/DC microgrid under unbalanced grid conditions. In Proceedings of the 2015 IEEE Energy Conversion Congress and Exposition (ECCE), Montreal, QC, Canada, 20-24 September 2015; pp. 4574-4581.

21. Vinifa, R.; Kavitha, A. Linear quadratic regulator based current control of grid connected inverter for Renewable Energy Applications. In Proceedings of the 2016 International Conference on Energy Efficient Technologies for Sustainability (ICEETS), Nagercoil, India, 7-8 April 2016; pp. 106-111.

22. Sutikno, H.; Jasa, L.; Ashari, M.; Purnomo, M.H. Optimal Control for Three-Phase Power Converters SVPWM Based on Linear Quadratic Regulator. Int. J. Acad. Res. 2012, 4, 177-186.

23. Hasanzadeh, A.; Edrington, C.S.; Maghsoudlou, B.; Mokhtari, H. Optimal LQR-based multi-loop linear control strategy for UPS inverter applications using resonant controller. In Proceedings of the 2011 50th IEEE Conference on Decision and Control and European Control Conference, Orlando, FL, USA, 12-15 December 2011; pp. 3080-3085.

24. Salim, R.; Kanaan, H.Y.; Al-Haddad, K.; Khedjar, B. LQR with integral action controller applied to a three-phase three-switch three-level AC/DC converter. In Proceedings of the 36th Annual Conference on IEEE Industrial Electronics Society (IECON 2010), Glendale, AZ, USA, 7-10 November 2010; pp. 550-555.

25. Loh, P.C.; Li, D.; Chai, Y.K.; Blaabjerg, F. Hybrid AC-DC Microgrids with Energy Storages and Progressive Energy Flow Tuning. IEEE Trans. Power Electron. 2013, 28, 1533-1543. [CrossRef]

26. Unamuno, E.; Barrena, J.A. Primary Control Operation Modes in Islanded Hybrid AC/DC Microgrids. In Proceedings of the IEEE International Conference on Computer as a Tool (EUROCON 2015), Salamanca, Spain, 8-11 September 2015.

27. Komurcugil, H.; Kukrer, O. Lyapunov-based control for three-phase PWM AC/DC voltage-source converters. IEEE Trans. Power Electron. 1998, 13, 801-813. [CrossRef]

28. Kim, S.K.; Choi, D.K.; Lee, K.B.; Lee, Y.I. Offset-Free Model Predictive Control for the Power Control of Three-Phase AC/DC Converters. IEEE Trans. Ind. Electron. 2015, 62, 7114-7126. [CrossRef]

29. Misra, P. LQR design with prescribed damping and degree of stability. In Proceedings of the Joint Conference on Control Applications Intelligent Control and Computer Aided Control System Design, Dearborn, MI, USA, 15-18 September 1996; pp. 68-70.

(C) 2017 by the authors. Licensee MDPI, Basel, Switzerland. This article is an open access article distributed under the terms and conditions of the Creative Commons Attribution (CC BY) license (http://creativecommons.org/licenses/by/4.0/). 